\title{
Bounded learning by doing, inequality, and multi-sector growth: A middle-class perspective.
}

\author{
Alain Desdoigts ${ }^{\dagger}$ and Fernando Jaramillo ${ }^{\ddagger}$
}

July, 2018

\begin{abstract}
This study presents a multisector model of middle-class-led economic growth, whereby, on the one hand, the middle class plays a key role in determining technical progress, while, on the other hand, both its size and income share are the result of past economic growth. Learning by doing, which is assumed to be sector-specific, bounded from above, and constrained by a minimum scale restriction, is the primary source of productivity gains. The emphasis is then placed on the entire income distribution, which affects the composition of demand -span of goods consumed- and in turn, the speed and the extent of the learning process in the set of goods produced. The model exhibits an inverted-U relationship between inequality and economic growth, which reflects the following trade-off: An economy cannot learn both quickly and simultaneously in a wide range of sectors. It is constrained in this respect by its income/skill distribution and the size of its labor force, with consequences on growth-enhancing strategies by means of income redistributions.
\end{abstract}

JEL Classification: D31, L16, O33, O40.

Keywords: Learning by doing, Middle-class-led consumption, Inequality, Multi-sector growth, Income redistribution.

\footnotetext{
${ }^{0 \dagger}$ Alain Desdoigts, IEDES université Paris 1 Panthéon-Sorbonne, Campus du Jardin d'agronomie tropicale de Paris, 45 bis, Av. de la Belle Gabrielle, 94736 Nogent-sur-Marne Cedex, France. alain.desdoigts@univ-paris1.fr.

$\ddagger$ Corresponding author: Fernando Jaramillo, Universidad del Rosario, Calle 14 \# 4-69, Bogotá, Colombia. fernando.jaramillo@urosario.edu.co

This work has benefitted from the generous support of our institutions. We would like to thank audiences at the $8^{\text {th }}$ Annual Conference on Economic Growth and Development (Indian Statistical Institute, New Delhi), International Workshop on Economic Growth, Macroeconomic Dynamics and Agents' Heterogeneity (European University at St. Petersburg), $14^{\text {th }}$ EUROFRAME Conference on Growth and Inequality: Challenges for EU Countries (German Institute for Economic Research at Berlin), Paris School of Economics, CREM (université de Rennes 1), Aix-Marseille School of Economics, Banco de la Republica de Colombia, THEMA (université de Cergy-Pontoise), Universidad de Antioquia (Medellín), and Universidad de Los Andes (Bogotá).
} 


\section{Introduction}

If, in the past, the emergence of a middle class characterized the industrial revolutions experienced by Western economies in the 18th and 19th centuries, ${ }^{1}$ the beginning of the 21st century has marked the end of their two centuries of hegemony: "Increasingly, the most important engine of growth for countries of the South is their domestic market. The middle class is growing in size and median income" (Human Development Report 2013). Nowadays, it has therefore become common in the press as well as in policy circles to wonder about the relative strength of the middle class and its role in economic development. This is reflected in public debates and even in some government initiatives (see, for example, President Obama's "Middle-Class Economics").

What of the emergence of a significant middle class and its corollary mass consumption on the one hand and production diversification on the other? Through which channels does a strong middle class have a crucial impact on economic growth: product and process-innovations, trickle-down effect, dynamic big push switching of technologies from small- to large-scale production or in other words, from traditional to modern technology? What are the consequences of redistributive policies? Do they lead to either strengthening or weakening the purchasing power of the so-called middle class?

In this study, we develop a multisector model of economic growth in which technological progress is driven by learning by doing in those sectors of activity that benefit from middle-class-led consumption. A key feature is that both the size of the middle class and its total income share are simultaneously an input to our model and an outcome of past economic growth. We focus on the entire income distribution as a factor that explains how some economies can emerge by fostering sectors of activity in order to implement increasing returns to scale, to learn at a faster or slower rate, to eventually reach maturity. ${ }^{2}$

Neither do we approach the middle class in an ad hoc manner (e.g. the middle quintile share, between the 4 th and the 9 th income deciles or $\$ 2$ and $\$ 10$ a day in LDCs), as is often the case in the associated empirical literature (see, Easterly 2001, Banerjee and Duflo 2008, and Ravallion 2010, among

\footnotetext{
${ }^{1}$ See, for example, Adelman and Morris (1967) and Landes (1998) as quoted in Easterly (2001, p. 318), who finds that relatively homogeneous middle-class countries have on average more income and growth.

${ }^{2}$ In taking a look back in time, we cannot afford to not refer to Kuznets' major contribution to the area. See, for example, Kuznets $(1955,1966)$, in whose footsteps we follow, for an analysis of inequality and structural change as characterized by an increase in the scale of productive units and shifts in the structure of consumption.
} 
others), nor do we consider the middle class as a potentially influential actor in relation to policies, governance, or changes in institutions (Birdsall 2010, Halter et al. 2014). Our model only relies on economic mechanisms to qualify and determine the importance of a strong middle class to an economy. ${ }^{3}$ Banerjee and Duflo (2008) put forward three arguments for explaining why a strong middle class may help to foster growth: i) entrepreneurs who boost innovation; ii) accumulation of human capital and savings; iii) diversification and expansion of markets via transfers of knowledge and scale economies. Our model builds on the last argument and focuses on the dynamic interplay between the composition of aggregate demand, which is determined by the shape of the income distribution, knowledge sharing facilitated by labor mobility, and learning by doing, which is assumed to be sector-specific, bounded from above, and endogenously constrained by a minimum scale restriction. ${ }^{4}$

In his introduction to the Handbook of Economic Growth (2005), Robert Solow regrets the profession's lack of interest in interactions between supply and demand. A proposed channel to investigate such interactions is by relaxing the traditional assumption of homothetic preferences, which neutralizes demand in long-run growth. The adoption of a hierarchical structure of preferences and indivisible consumption, in which income at the household level affects the extensive margin of consumption -span of varieties consumed- and their impact on economic growth is examined, for instance, in Zweimüller (2000), Foellmi and Zweimüller (2006) and, closer in spirit to the present paper, Foellmi, Wuergler and Zweimüller (2014). We trace their footsteps here. Our setup also allows for hierarchies of needs, and economic growth is an endogenous outcome of the economic system. However, in contrast with the above mentioned papers, inequality does not affect the composition of R\&D. Instead, similar to Stokey (1988), Young (1991, 1993), Lucas (1993), and in line with the work of Matsuyama (2002) on mass consumption, technological progress is the by-product of economic activity in which learning by doing is the main source of productivity gains, and where the shape of the income distribution affects the speed and the extent of the learning process. Thus, this contribution should be seen as a complementary rather than a competing model. We place emphasis on the implementation process, which takes time to develop and to learn after an invention has taken place, rather

\footnotetext{
${ }^{3}$ See, for politico-economic models of growth that exhibit the endogenous emergence of a middle class, Acemoglu and Robinson (2000) and Bourguignon and Verdier (2000), among others.

${ }^{4}$ See Falkinger and Zweimüller (1996) who find that the composition of demand depends on both the level and distribution of income, and Argote and Epple (1990), Bahk and Gort (1993), and Thompson (2001), among others, who provide evidence of a significant impact of learning by doing on productivity.
} 
than on the innovation process per se.

Craft (1996) emphasizes learning effects as an interesting way to analyze growth during the First Industrial Revolution. As Bessen puts it (2015, p. 38) "Single technological ideas don't transform society; knowledge does... Major new technologies typically go through long periods of sequential innovation, where a string of improvements, new knowledge, and new skills are developed one after the other. Central to this process - and why it takes so long - is learning by doing." Bessen also underlines the importance of significant economies of scale involved in mature technologies, which are most often implemented by a few large firms. He illustrates his point by using the example of the automobile, stating that "the automobile became revolutionary only after a large number of incremental innovations improved the technology and a large body of mundane, detailed knowledge developed among assembly workers, drivers, mechanics, road builders, and others. And this transformation took many decades." Today, the automobile sector is dominated by a small number of large firms with a clear tendency to merge over the last twenty years, whereas, a century ago the sector was dominated by a large number of small-scale innovative entrepreneurs.

Based on this premise, the core mechanisms of our middle-class-led growth model are threefold. Firstly, learning takes place in an intermediate range of sectors, where demand is high enough to allow a firm to take advantage of scale economies, and where the learning possibilities have not yet been exhausted. Secondly, how much can a firm gain in terms of cost reduction is determined by its accumulated experience resulting from cumulative output, driven by its market size evolution, which in turn depends on the shape of the income distribution. On the one hand, this illustrates how the income distribution determines the intensity of learning specific to each sector. On the other hand, we show that whether learning takes place across a broad range of sectors or not, depend on the distribution of income. Hence, if the income distribution determines where labor is allocated in the economy, the middle class is specified in such a way that it determines where and for how long learning takes place. Thirdly, sustained growth requires technology providing increasing returns be implemented in sectors one after another. Knowledge exchange resulting in productivity gains must create sufficient additional demand in higher-ranking goods in the consumer's hierarchy of needs, so that learning never ceases. ${ }^{5}$ Only then will the economy move

\footnotetext{
${ }^{5}$ Bessen (2015) begins the introduction to his book Learning by doing with the following statement "The effects of new technology are all around us." This is a phenomenon that cannot be denied, whether one has in mind the agro-food, the auto, the computer industries, tourism or start-up companies. Today, radio frequency identification is an example of this.
} 
ahead.

Our study also deals with the two following issues: How does a more equal distribution foster economic growth; how does the middle class impact learning at a macro level and, consequently, economic growth? We first show that only a smooth income distribution may lead to long-run growth; that is, either a polarized or a degenerate distribution is a drag on growth. On the one hand, in a highly unequal economy, where an elite owns nearly all of the wealth, scale economies are confined to a small range of sectors with limited opportunities for learning. There are no middle-market consumers, and that leads to stagnation. On the other hand, an economy with an almost perfectly egalitarian income distribution needs to have a large population and/or a low minimum scale restriction to be able to ignite the learning process and achieve positive growth in the long run. Second, our model unveils a mechanism through which an inverted-U relationship between inequality and sustained growth emerges. ${ }^{6}$ This inverted U-shaped curve reflects the trade-off between allocating labor to a broad range of sectors in which learning may take place and the speed of the learning process in each sector, where the allocation of labor is driven by the composition of aggregate demand. Put differently, the trade-off consists in learning quickly in a small number of sectors versus learning more slowly in a wide range of sectors. Such a trade-off is, for the most part, influenced by the distribution of income, which governs the duration and the extent of the learning process and, eventually, changes in the diversification to sectors.

Our model, therefore, has implications for growth-enhancing strategies by means of specific redistributions of income. In particular, it brings a theoretical framework, in which redistributing from the upper class to the middle and lower classes positively impacts long-run economic growth. This is in contrast with Matsuyama (2002) who shows that a critical mass of rich households is needed for an industry to take off, which results in lower prices and triggers a sound trickle-down process, so that poorer households may eventually purchase additional goods, which further lowers prices giving rise thereafter to a trickle-up mechanism, and so on. It also differs from Foellmi and Zweimüller (2006) who develop an innovation-based model where more income inequality (i.e. a higher income ratio of rich to poor and/or a higher concentration of income among the rich) increases growth by raising the present value of profits derived from the invention of new products that only rich households are initially willing to pay for. We believe our model

\footnotetext{
${ }^{6}$ Note that Banerjee and Duflo (2003) find a non-linear empirical relationship between inequality and growth, where a shift in the income distribution may negatively affect economic growth whether the distribution becomes more unequal or more egalitarian.
} 
is more appropriate to account for the economic development of countries in which either R\&D is limited and technology adoption conditional on its learning potential (e.g. developing countries) or where the expected trickledown process may be ineffective due to, for instance, a too large income gap between the upper and the middle class. Finally, Foellmi et al. (2014) distinguish the invention of new high-quality products only accessible to the rich, from process innovations that transform luxury goods into low-quality mass products, which then become affordable to the lower classes. Such product life cycles differ from our chosen dynamic big push switching of technologies (i.e. à la Murphy et al. 1989) where all the action takes place along the extensive margin. ${ }^{7}$ Hence, rather than the relative price dynamics between either luxuries and necessary items or goods of different quality, it is the change in the profile of the distribution of nominal income relative to the consumer price index that is crucial in our multisector model of middleclass-led economic growth.

Because we examine the role that income distribution plays in the dynamics of the sector structure in the economy, this paper adds a new perspective to the recent empirical area of research on long-run demand and supply drivers of structural change (Herrendorf et al. 2013, Boppart 2014, Comin et al. 2017, among others). But, in contrast to these authors, we view structural changes accompanying economic development as more widespread than the traditional shift from agriculture to manufacturing and then from manufacturing to services. In that way, our study is more closely related to the theoretical work carried out by Zeira and Zoabi (2015) who interpret structural changes as the transition between traditional and modern technologies in a growing economy where, interestingly enough, growth is driven by rising productivity in modern sectors only. They treat countries as small, open economies that benefit from new technologies invented elsewhere and as such assume that productivity in modern sectors rises exogenously over time. Here, we consider that introducing both learning by doing and skill distribution is relevant to assess a country's capacity to adopt and implement new technologies.

Last but not least, "[...] redistributive policies - such as progressive taxation and social welfare - are likely to facilitate growth through their impact on the bottom of the distribution, and to inhibit growth through their impact on the top of the distribution" (Voitchovsky 2005, p. 290). If this empir-

\footnotetext{
${ }^{7}$ Under certain conditions, our development process may follow a fairly similar pattern to Matsuyama's (2002) flying-wild-geese model. However, it should be noted that the mechanisms and, more specifically, the product life cycles underlying uneven sectoral growth are a lot different from each other: trickle-down effect in a context of competitive markets versus big push switching of technologies.
} 
ical finding supports the results of both innovation-based and trickle-down models, it is also consistent with our approach that advocates income transformations in favor of either the middle class or the lower class at the expense of the upper class.

The rest of the paper is organized as follows. In Section 2, we present the model with regards to which these issues can be formally analyzed. Section 3 discusses our set up regarding knowledge-based productivity growth. It analyzes the interplay between middle-class-led consumption, the extent and speed of the learning process, and the aggregate rate of growth. Section 4 characterizes the emergence of the middle class as an outcome of past economic growth and the steady-state growth rate. In Section 5, the nexus between inequality and growth is discussed. We take a special interest in the conditions for the (re)distribution of income required for sustained growth. This section also explains the "range-speed" of the learning trade-off, which yields an inverted-U relationship between inequality and growth. Section 6 concludes.

\section{The model}

Our framework builds on the seminal work of Murphy, Shleifer, and Vishny (1989) who formalized the study on demand linkages of early development economists such as Rosenstein-Rodan (1943) and Hirschman (1958), whose theories stress scale economies and complementarities as primary causes of economic growth. ${ }^{8}$

\subsection{Households' non-homothetic preferences, distrib- ution of skills, and budget constraints}

It is assumed that all households have the same preferences. They are modeled via a utility function that is defined over a continuum of indivisible goods $q \in(0, \infty)$ such that, at each date $t$,

$$
V(t)=\int_{0}^{\infty} \frac{1}{q} \imath(q, t) d q
$$

where $\imath(q, t)$ is an indicator function that takes a value of either one or zero according to:

\footnotetext{
${ }^{8}$ Desdoigts and Jaramillo (2009) set up a fairly similar in its premise, static twocountry trade model in which they investigate international demand spillovers brought about by an emerging global middle class, and their impact on trade patterns and (deindustrialization.
} 


$$
\imath(q, t)=\left\{\begin{array}{cc}
1 & \text { if the agent consumes } q \\
0 & \text { otherwise }
\end{array} .\right.
$$

Thus, a household's utility increases with the range of goods $(0, q)$ it consumes and not with the consumption of a single good $q$. Consumption is hierarchically structured, that is, needs are ordered so that the proportion of income that households spend on lower-indexed goods or, equivalently, on goods with lower income elasticities of demand, decreases with a household's income. Different goods have different priorities in consumption and richer households can consume more than the bundle of goods available to poorer households (see Bertola, Foellmi and Zweimüller 2006, Chapter 12).

Labor is the only input and households are organized by skill level, denoted by $\gamma L$, where $L$ is the labor force and $\gamma \leq \gamma<\infty$. Each household is identified by its $\gamma$ type. The skills of the labor force are distributed according to the cumulative distribution function $F(\gamma)$, which is assumed to be exogenous and constant over time. Thus, our framework allows us to distinguish between societies dominated by a highly educated elite and lacking semi-skilled and highly skilled workers, and societies that are endowed with a relatively large number of engineers, managers, and skilled workers.

At each date $t$, the labor income of a $\gamma$ type household is proportional to its skill level, which is given by $\gamma w(t) L$, where $w(t)$ is the wage per unit of skill. Should there be firms making a profit in the economy, to simplify the analysis and without loss of generality, it is assumed that it will be redistributed to households up to their type $\gamma$. The nominal income of a $\gamma$ type household is therefore defined as the sum of its labor income and income arising from shares it holds in profit-making firms:

$$
Y(\gamma, t)=\gamma[w(t) L+\Pi(t)]
$$

where $\Pi(t)$ denotes corporate profits.

Define $(0, q(\gamma, t))$ as the span of varieties purchased by a $\gamma$ type household at date $t$. The budget constraint that describes the consumption options available to this household with income $Y(\gamma, t)$ can be written as:

$$
\int_{0}^{q(\gamma, t)} p(q, t) \imath(q, t) d q=\gamma[w(t) L+\Pi(t)]=Y(\gamma, t) .
$$

At the household level, income (wages and profits) affects the extensive margin of consumption: the higher the household's income, the broader the span of varieties consumed. 


\subsection{Technology, market structure, and the equilibrium price}

Each good $q$ can be produced with two production function technologies. The first, loosely referred to as traditional, exhibits constant returns to scale (CRS). One unit of good $q$ requires $\alpha / A(t)$ units of labor, where $\alpha>1$ and $A(t)$ is knowledge-based productivity at time $t$. In our framework, such a technology is used to produce goods that possess the artisanal touch of luxuries. The alternative production technology, often described as modern, exhibits increasing returns to scale (IRS). Formally, $1 / A(t)$ units of labor are required to produce one unit of good $q$. Nevertheless, to produce at such a marginal cost, a firm must also be able to cover a fixed cost equal to $C / A(t)$ units of labor.

On the one hand, each good may be produced by a competitive fringe of firms with the CRS technology. Then, the free-entry equilibrium number of firms satisfies the zero-profit condition, and the equilibrium price is equal to the average cost:

$$
p(q, t)=p(t)=\alpha \frac{w(t)}{A(t)} .
$$

On the other hand, we show that if the distribution function $F(\gamma)$ is smooth enough, which rules out perfect equality, there is a unique Nash equilibrium for a monopoly implementing the IRS technology, ${ }^{9}$ which consists of setting the price at the same level as the competitive fringe (see Appendix 1). Therefore, the dynamics of the economy do not hinge on relative price effects, either through a trickle-down process or vertical product differentiation, but on the change over time in households' income relative to the consumer price index.

\subsection{Market demand and the static output multiplier}

If market demand is low, the goods are produced using the high-cost-constantreturns-to-scale technology. Instead, if market demand is sufficiently large, firms undertake the fixed cost investment allowing them to produce at lower marginal cost.

Let us define the demand for each good $q(t)$ as $x(q, t) \equiv[1-F(\gamma(q, t))] L$, where $\gamma(q, t)$ is the share of income of households whose purchasing power is high enough to purchase exactly $(0, q(t))$, and $F(\gamma(q, t))=0$ for $\gamma(q, t)<\underline{\gamma}$.

\footnotetext{
${ }^{9}$ The reality is that the market structure must lie between these two extremes, competitive fringe and monopoly. Our framework allows us to simply take into consideration the fact that mature technologies typically involve substantial economies of scale, and thus are most often implemented by a small number of large firms.
} 
Whenever the demand is high enough to cover the fixed cost, a good $q$ is produced by a monopolist that implements the IRS technology. Specifically, as soon as $L>C /(\alpha-1)$, a good $q$ is produced using the IRS technology if and only if the demand for this good is such that the following minimum efficiency scale is satisfied:

$$
(\alpha-1) \frac{w(t)}{A(t)} x(q, t)-\frac{w(t)}{A(t)} C \geq 0 \Leftrightarrow x(q, t) \geq \frac{C}{\alpha-1} .
$$

At each date $t$, there is a marginal good $q^{*}(t)$ such that the break-even condition $x\left(q^{*}, t\right)=C /(\alpha-1)$ holds true. Within our dynamic model, such a sector of activity can be said to have attained the takeoff stage, which recalls the big push switching of technologies à la Murphy et al. (1989). Note that $x\left(q^{*}, t\right)$ is exogenous and constant over time. Then, sectors that produce goods $q(t) \leq q^{*}(t)$ and $q(t)>q^{*}(t)$, use the IRS and CRS production technology, respectively. We define $\gamma^{*}(t)$ as the share of income held by this marginal household whose purchasing power allows purchasing exactly the range of goods $\left(0, q^{*}(t)\right)$, where

$q^{*}(t)=\frac{w(t) \gamma^{*}(t)[L+\Pi(t) / w(t)]}{p(t)}=\frac{A(t)}{\alpha} \gamma^{*}(t)\left[L+\frac{\Pi(t)}{w(t)}\right]$, and $\frac{w(t)}{p(t)}=\frac{A(t)}{\alpha}$.

We also define the upper class to be the set of households of type greater than $\gamma^{*}(t)$. There is a number $N^{*}(t)$ of such households, where

$$
N^{*}(t)=\left[1-F\left(\gamma^{*}(t)\right)\right] L .
$$

Their purchasing power allows them to buy goods produced with the IRS technology, as well as goods with higher income elasticity of demand that are produced using the CRS technology. We therefore have the following break-even condition, which is time-independent. (We thus get rid of the $t$ notation in both variables, $N^{*}$ and $\gamma^{*}$.)

$$
x\left(q^{*}, t\right)=N^{*}=\left[1-F\left(\gamma^{*}\right)\right] L=\frac{C}{\alpha-1} .
$$

Thus, learning is constrained by a minimum scale restriction, which depends on the distribution of income, the size of the labor force, and technical parameters (i.e. fixed cost and markup).

The aggregate profit in the economy is the sum of profits realized by those sectors of activity that produce goods $q$ in the range $\left(0, q^{*}(t)\right)$ :

$$
\Pi(t)=p(t) \int_{0}^{q^{*}(t)} x(q, t) d q-\int_{0}^{q^{*}(t)} \frac{w(t)}{A(t)}[x(q, t)+C] d q .
$$


Combining the above profit expression with (5) and (6) yields

$$
\frac{\Pi(t)}{p(t)}=\frac{\alpha-1}{\alpha} \frac{w(t) L+\Pi(t)}{p(t)} T
$$

where $T=L \int_{\underline{\gamma}}^{\gamma^{*}} \gamma d F(\gamma)$ is defined as the share of income held by those households of type smaller than $\gamma^{*}$ whose income is entirely devoted to purchasing mass-consumption goods in the range $\left(0, q^{*}(t)\right)$. From this definition, we deduce:

$$
\frac{\Pi(t)}{p(t)}=\frac{\alpha-1}{\alpha} \frac{1}{1-\frac{\alpha-1}{\alpha} T} \frac{w(t) L}{p(t)} T,
$$

where the output multiplier, which is independent of time, is defined by

$$
M=\frac{1}{1-\frac{\alpha-1}{\alpha} T} .
$$

As a consequence, the higher the real income per capita, denoted by $y(t)$, the lower the share of income held by the upper class, or, equivalently, the higher the share of income held by those households of type smaller than $\gamma^{*}$. This increases monotonically with both the output multiplier and knowledgebased productivity, and takes the form

$$
y(t)=\frac{Y(t)}{p(t) L}=\frac{w(t) L+\Pi(t)}{p(t) L}=\frac{1}{1-\frac{\alpha-1}{\alpha} T} \frac{A(t)}{\alpha}=M \frac{A(t)}{\alpha} .
$$

For now, the setting of the model is very much inspired by the static framework in Murphy, Shleifer and Vishny (1989). However, two questions remain, namely, what about the extent and the speed of the learning process, and how do they depend on the entire income distribution?

\subsection{Sectors of activity featuring learning by doing and the middle class}

In our dynamic framework, sectors grow at different rates. At each date $t$, learning leads to an accumulation of experience at the sector level, denoted by $E(q, t)$. The level of knowledge-based productivity in the economy, $A(t)$, then equals the sum of experiences gathered over time by all sectors that have implemented the IRS technology. Specifically, the accumulated stock of knowledge at time $t$ is defined by

$$
A(t)=\int_{0}^{q^{*}(t)} E(q, t) d q
$$


Experience increases with cumulative production levels, and the following functional form for the experience accumulated in sector $q(t)$ over time interval $\left(t^{*}(q), t\right)$ is adopted (see Melitz 2001):

$$
E(q, t)=\left\{\begin{array}{lc}
\lambda \widetilde{E} \int_{t^{*}(q)}^{t} x(q, v) d v \quad \text { if } \int_{t^{*}(q)}^{t} x(q, v) d v<1 / \lambda \\
\widetilde{E} & \text { otherwise }
\end{array}\right.
$$

where $\lambda>0$ describes the learning rate, $t^{*}(q)$ denotes the date at which the IRS technology was adopted for the first time by the activity sector that produces good $q(t)$, and $x(q, v)$ is the level of output produced in this activity sector at time $v, t^{*}(q) \leq v \leq t .{ }^{10}$ Hence, learning in every sector of activity is not only constrained by a minimal-scale restriction but is also bounded from above, the upper bound being defined by $\widetilde{E}$, which is assumed to be exogenous and constant, both across sectors and over time. ${ }^{11}$

At each date $t$, among those sectors of activity that use the IRS technology, we can distinguish between two groups of sectors. The first group includes sectors where learning is depleted and has reached the upper bound, whereas the second group includes those in which the accumulated experience has not yet reached the upper bound. This group of sectors lies within the range of activities $\left(\widetilde{q}(t), q^{*}(t)\right)$, where $\widetilde{q}(t)$ is defined by

$$
E(\widetilde{q}, t)=\widetilde{E} \Leftrightarrow \int_{t^{*}(\widetilde{q})}^{t} x(\widetilde{q}, v) d v=1 / \lambda,
$$

and where $t-t^{*}(\widetilde{q})$ denotes the time elapsed since good $\widetilde{q}(t)$ was first produced using the IRS technology.

$$
\text { As soon as } \int_{t^{*}(q)}^{t} x(q, v) d v \geq 1 / \lambda \text {, learning in sector } q \text { has reached the }
$$
upper bound $\widetilde{E}$, that is, the sector of activity has reached maturity. In addition to $q^{*}(t)$, there exists another marginal sector, $\widetilde{q}(t)$, which is defined as the most recent sector of activity at time $t$ where learning has declined to zero. Solving (11) yields a solution for $\widetilde{q}(t)$. It follows that, similar to the $\gamma^{*}$

\footnotetext{
${ }^{10}$ We follow here the literature on learning to describe progress reached at the sector level. Equation (10) is a simplified form of a more comprehensive formulation as it appears, for example, in Thompson (2010).

${ }^{11}$ Similar to Lucas (1993) and Young (1993), amongst others, we allow for transfers of knowledge across sectors. Therefore, learning may not necessarily be bounded at the aggregate level and all sectors of activity have a chance to benefit from productivity gains over time. For instance, the primary sector that produces necessary products is nowadays benefiting most from the knowledge accumulated in other sectors, such as mechanization of agriculture, chemistry (e.g. pesticides, fertilizers), agriculture v3.0 and geolocation, etc.
} 
type household, there is another key marginal household of type $\widetilde{\gamma}(t)$ whose purchasing power allows buying exactly the range of goods $(0, \widetilde{q}(t))$. Thus, our framework allows us to provide an economic definition of who belongs to the middle class, although we acknowledge that the term may mean different things depending on one's perspective.

Definition 1 If households of type $\gamma^{*}$ and above constitute the upper-income class, as long as $\gamma<\widetilde{\gamma}(t) \leq \gamma^{*}$, mass consumers (the rest) may now be divided into a low-income class, which includes households of types between $\gamma$ and $\widetilde{\gamma}(t)$, and a middle-income class where we find households of types ranging from $\widetilde{\gamma}(t)$ to $\gamma^{*}$. If $\widetilde{\gamma}(t) \leq \underline{\gamma}$, the economy is composed of only two classes: the upper-income class and the rest.

Learning eventually occurs only in an intermediate range of sectors of activity $\left(\widetilde{q}(t), q^{*}(t)\right)$, that is, those for which there is enough demand to prompt the learning process but that have not yet exhausted the learning possibilities. In contrast to the empirical literature on this subject, which identifies the middle class by setting limits either in the people space (e.g. the middle 60 percent) or the income space (e.g. $75 \%-125 \%$ of the median income), we stress the importance of the size of the middle class in conjunction with its income share as key determinants of sustained economic growth (see, discussions by Atkinson and Brandolini 2013 and Dallinger 2013, among others).

\section{Middle-class-led consumption, learning curves, and growth}

\subsection{Distribution of income, production diversification, and aggregate economic growth}

Knowledge-based productivity $A(t)$ is a function of the experience accumulated by all sectors of the economy in which learning occurs and has already taken place at time $t$. We thus rewrite (9) as

$$
A(t)=\int_{0}^{q^{*}(t)} E(q, t) d q=\widetilde{E} \widetilde{q}(t)+\int_{\widetilde{q}(t)}^{q^{*}(t)} E(q, t) d q .
$$

Changes in $A(t)$ are the result of the experience accumulated in the economy at time $t$ :

$$
\dot{A}(t)=\int_{\widetilde{q}(t)}^{q^{*}(t)} \dot{E}(q, t) d q=\lambda \widetilde{E} \int_{\widetilde{q}(t)}^{q^{*}(t)} x(q, t) d q,
$$


and

$$
\begin{aligned}
& \dot{E}(q, t)=\left\{\begin{array}{lc}
\lambda \widetilde{E} x(q, t) & \text { if } E(q, t)<\widetilde{E} \text { and } \widetilde{q}(t)<q \leq q^{*}(t) \\
0 & \text { otherwise }
\end{array} \Leftrightarrow\right. \\
& \frac{\dot{E}(q, t)}{E(q, t)}=\left\{\begin{array}{c}
x(q, t) /\left[\int_{t^{*}(q)}^{t} x(q, v) d v\right] \quad \text { if } E(q, t)<\widetilde{E} \text { and } \widetilde{q}(t)<q \leq q^{*}(t) . \\
0 \quad \text { otherwise }
\end{array}\right.
\end{aligned}
$$

Accumulated experience is a by-product of the economic activity in those sectors where there is mass consumption.

It is worth noting here that given $x(q, t)=[1-F(\gamma(q, t))] L$, the evolution of demand in sector $q$ is at the origin of its learning curve, which explicitly depends on the survival function of the distribution of income. This yields the following productivity rate of growth arising from economy-wide learning by doing:

$$
g(t)=\frac{\dot{A}(t)}{A(t)}=\lambda \widetilde{E} \int_{\widetilde{q}(t)}^{q^{*}(t)} \frac{x(q, t)}{A(t)} d q=\lambda \widetilde{E} \int_{\widetilde{q}(t)}^{q^{*}(t)} \frac{[1-F(\gamma(q, t))] L}{A(t)} d q .
$$

At each time $t$, the growth rate of knowledge-based productivity equals the amount of labor (excluding fixed costs) required to produce quantity $x(q, t)$ in sectors using the IRS technology and in which learning takes place. Thus, unit cost reductions as a result of increased knowledge arise from increased cumulative output brought about by both learning and economies of scale.

Whereas $q^{*}(t)$ evolves over time, recall that $\gamma^{*}$ is constant over time and equal to $q^{*}(t) / y(t) L$ (see $(2)$ and $\left.(8)\right)$. We use the change in variables $\gamma(q, t)=$ $q / y(t) L$ to rewrite $(12)$ :

$$
g(t)=\lambda \widetilde{E} \frac{y(t) L}{A(t)} \int_{\widetilde{\gamma}(t)}^{\gamma^{*}}[1-F(\gamma)] L d \gamma
$$

This discussion allows us to establish the following first important result.

Proposition 1 The rate of growth of $A(t)$ is positively associated with the output multiplier. It increases with the share of income held by those households of type smaller than $\gamma^{*}$ and the proportion of total income held by the middle class, and is equal to:

$$
g(t)=\lambda \widetilde{E} \frac{M}{\alpha} L\left[\gamma^{*} N^{*}+T-[\widetilde{\gamma}(t) \widetilde{N}(t)+\widetilde{T}(t)]\right],
$$




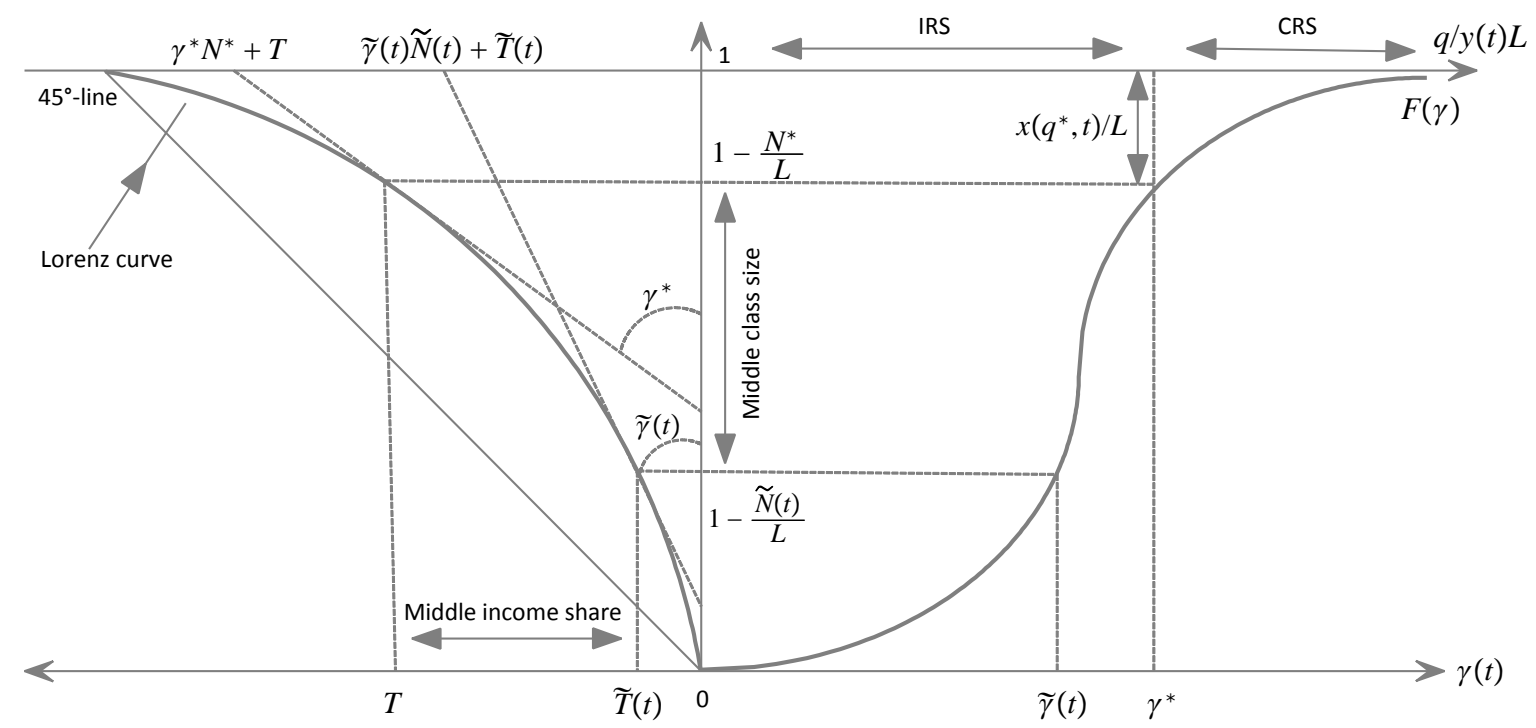

Figure 1: Middle-class identification and growth. Right quadrant: cumulative incone distribution $F(\gamma)$ and lower and upper cutoffs $\widetilde{\gamma}(t)$ and $\gamma^{*}$, respectively. Left quadrant: Lorenz curve, and middle-class size $\widetilde{N}(t)-N^{*}$ and income share $T-\widetilde{T}(t)$.

where $M / \alpha=y(t) / A(t), \widetilde{N}(t)=[1-F(\widetilde{\gamma}(t))] L$, and $\widetilde{T}(t)=\int_{\underline{\gamma}}^{\widetilde{\gamma}(t)} \gamma f(\gamma) L d \gamma$. Whenever $\widetilde{q}(t)<\underline{q}(t)$, which implies that $\widetilde{\gamma}(t)<\underline{\gamma}$, we have $F(\widetilde{\gamma}(t))=$ $f(\widetilde{\gamma}(t))=0$, which yields $\widetilde{N}(t)=L$ and $\widetilde{T}(t)=0$.

Proof. Replacing (8) in (13) and integrating by parts $\int_{\widetilde{\gamma}(t)}^{\gamma^{*}}[1-F(\gamma)] L d \gamma$, we obtain (14).

Figure 1, which is inspired by Atkinson and Brandolini (2013), contains two graphical representations: the left one is the Lorenz curve, associated with the cumulative income distribution $F(\gamma)$, which is shown on the right. Similar to the model of Murphy, Shleifer, and Vishny (1989) without learning, $\gamma^{*} N^{*}+T$ is the proportion of total income spent in sectors that have implemented the IRS technology (see the left-hand panel on Figure 1). The growth rate at time $t$ depends on both the output multiplier and the proportion of income that is spent in sectors where learning takes place and is not yet exhausted, that is, given (8), on total income spent in the range of sectors $\left(\widetilde{q}(t), q^{*}(t)\right)$. Therefore, (14) provides us with a relationship between growth and middle-class-led consumption, where growth depends on the share of ag- 
gregate real income held by those households of type between $\widetilde{\gamma}(t)$ and $\gamma^{*}$. The proportion of total income spent in the intermediate range of sectors $\left(\widetilde{q}(t), q^{*}(t)\right)$ where learning takes place depends on both the size of the middle class $\tilde{N}(t)-N^{*}$ and the share of total income held by the middle class $T-\widetilde{T}(t)$. Intuitively, a given middle-class share of total income may be high, but concentrated among either a large or a small number of middle-class consumers, which depends on the shape of the income distribution. Thus, the entire income distribution and, more specifically, the middle class identified by its lower and upper bounds, $\widetilde{\gamma}(t)$ and $\gamma^{*}$, respectively, determines the extent of the learning process.

The right-hand panel on Figure 1 shows where the expenditure of various consumers goes, and represents sectors of activity where learning takes place. Indeed, as alluded to earlier, we have $\gamma(q, t)=q / y(t) L$. Thus, it also allows us to determine the product development cycle, which moves through three phases. During its first phase, demand is too low for a firm to implement the IRS technology. Only the privileged upper class has access to a good that is produced using a CRS production function by a competitive fringe. At this stage, no learning takes place. However, learning may take place in upstream sectors that produce higher-priority goods in the hierarchy of needs, which leads to an increase in the real income of the middle class, giving some of its members access to goods that were previously categorized as luxury goods and were only affordable by the upper class. This is the second phase of the product cycle: the good is now produced with increasing returns and a learning phase takes place. Finally, learning eventually ceases and the good becomes affordable by a large number of consumers, including the poor.

\subsection{Distribution of income and the speed of learning}

In the long run, as long as there is positive growth, a sector of activity $q$ begins producing good $q$ with the CRS technology. At this stage, $q$ can be considered a luxury good and does not represent an essential need for consumers. It is produced for specific consumers, namely the highest-income households $N^{*}$ of type greater than $\gamma^{*}$. Then, it may go through a stage where it becomes, at some point in time, the marginal sector $q^{*}(t)$. It produces $q$ in the amount $x\left(q^{*}, t\right)=\left[1-F\left(\gamma^{*}\right)\right] L$. From then on, it starts to accumulate experience, the magnitude of which depends on aggregate economic growth and the distribution of income. Its apprenticeship may continue until the point of exhaustion, that is, until it has reached the upper bound $\widetilde{E}$. When the sector has exhausted its potential for learning, it becomes a marginal sector of activity $\widetilde{q}(t)$ whose good is purchased in quantity $x(\widetilde{q}, t)=[1-F(\widetilde{\gamma}(t))] L$ 
(see the right-hand panel on Figure 1).

How long does it take for a sector to reach the upper bound $\widetilde{E}$, that is, to reach maturity? What is the duration of the learning period? The analysis below can be seen as a survival analysis in which we are interested in the length of time before the upper bound is reached by a sector once it has implemented the IRS technology.

Note first that the experience accumulated by one sector of activity depends on its market size and growth rates over the period prior to the point at which it reaches $\widetilde{E}$. Thus, changes in the demand structure depend on aggregate economic growth and the income distribution. As long as aggregate economic growth is taking place, the growing demand in a sector of activity depends on the hazard rate of the income distribution: if $y(t)$ increases by $1 \%$ during the learning process, the demand for good $q$ increases by $\gamma(q, t)$ times the hazard rate $f(\gamma(q, t)) /[1-F(\gamma(q, t))]$. More specifically, the income elasticity of demand for any good $q$ at time $t$ depends on the hazard rate of the income distribution $f(\gamma(q, t)) /[1-F(\gamma(q, t))]$, which is the number of households of type $\gamma(q, t)$ relative to the number of households whose income is greater than $\gamma(q, t)$. Specifically, we have ${ }^{12}$

$$
\frac{\dot{x}(q, t)}{x(q, t)} / \frac{\dot{y}(t)}{y(t)}=\gamma(q, t) \frac{f(\gamma(q, t))}{1-F(\gamma(q, t))} .
$$

Second, recall from (10) that for all $q \in\left(\widetilde{q}(t), q^{*}(t)\right)$, the experience accumulated at time $t$ by the sector of activity indexed by $q$ is described using the survival function $1-F(\gamma(q, t))$ :

$$
\frac{E(q, t)}{\widetilde{E}}=\lambda \int_{t^{*}(q)}^{t} x(q, v) d v=\lambda \int_{t^{*}(q)}^{t}[1-F(\gamma(q, v))] L d v .
$$

Learning duration is determined by the law of motion of demand for $\widetilde{q}$ over the learning period. Specifically, the learning process in the sector of activity $\widetilde{q}$ that has reached maturity $\widetilde{E}$ at time $t$ has a duration of $t-t^{*}(\widetilde{q})$,

\footnotetext{
${ }^{12}$ Note that

$$
\dot{x}(q, t)=\frac{\partial[1-F(\gamma(q, t))] L}{\partial t}=-f(\gamma(q, t)) L \frac{\partial \gamma(q, t)}{\partial t},
$$

where $\gamma(q, t)=q / y(t) L$ implies that $\partial \gamma(q, t) / \partial t=-\left(q / y^{2}(t) L\right)(\partial y(t) / \partial t)$. We get

$$
\dot{x}(q, t)=f(\gamma(q, t)) \gamma(q, t) L \frac{\dot{y}(t)}{y(t)} \Rightarrow \frac{\dot{x}(q, t)}{x(q, t)}=\gamma(q, t) \frac{f(\gamma(q, t))}{1-F(\gamma(q, t))} \frac{\dot{y}(t)}{y(t)} .
$$
}


where $t^{*}(\widetilde{q})$ is such that:

$$
\begin{aligned}
\frac{E(\widetilde{q}, t)}{\widetilde{E}} & =1 \Leftrightarrow \int_{t^{*}(\widetilde{q})}^{t} x(\widetilde{q}, v) d v=\int_{t^{*}(\widetilde{q})}^{t}[1-F(\widetilde{\gamma}(v))] L d v=\frac{1}{\lambda}, \\
\text { with } \widetilde{\gamma}(v) & =\gamma^{*} \exp \left(\int_{t^{*}(\widetilde{q})}^{v} g(\widetilde{q}, m) d m\right),
\end{aligned}
$$

and $g(\widetilde{q}, m)=\dot{x}(\widetilde{q}, m) / x(\widetilde{q}, m)$ is the rate of change that the sector of activity $\widetilde{q}$ experiences at time $m$. Note that when $\widetilde{\gamma}(v)<\gamma$, then $F(\widetilde{\gamma}(v))=0$.

Firstly, learning duration is thus determined by the law of motion of demand for $\widetilde{q}$ over the time interval $\left(t^{*}(\widetilde{q}), t\right)$, where changes in demand depend on the income elasticity of demand for $\widetilde{q}$, which itself evolves over the learning process according to both aggregate economic growth $\dot{y}(v) / y(v)$ and the hazard rate $f(\widetilde{\gamma}(v)) /[1-F(\widetilde{\gamma}(v))]$. Secondly, implicit differentiation of (16) leads to the following inequality, where the higher prior economic growth in the $\widetilde{q}$ sector, the shorter the duration of the learning process:

$$
\frac{d\left(t-t^{*}(\widetilde{q})\right)}{d g(\widetilde{q}, \check{t})} \leq 0, \forall t^{*}(\widetilde{q}) \leq \check{t} \leq t
$$

Finally, the shape of the income distribution in the range $\left(\widetilde{\gamma}(t), \gamma^{*}\right)$ or, equivalently, $\left(\widetilde{q}(t) / y(t) L, q^{*}(t) / y(t) L\right)$, determines the duration of the lifelong learning process in a sector of activity: the higher the growth rate of demand, the shorter the apprenticeship period and the sooner the sector reaches maturity.

\section{The middle class as both an input and an outcome of growth}

It is now clear that the combined composition of aggregate demand and the learning process as determined by the entire income distribution implies that mass consumption at time $t$ of the intermediate range of goods $\left(\widetilde{q}(t), q^{*}(t)\right)$ is the engine of growth that enables an economy to keep moving forward. We now turn to the identification of the middle class (i.e. households of type ranking from $\widetilde{\gamma}(t)$ to $\gamma^{*}$, which is derived from past economic growth.

\subsection{The size of the middle class increases with past economic growth}

Recall that the upper cutoff, which demarcates the middle class from the upper class $\gamma^{*}$, is determined regardless of the state of economic growth. 
It depends on the income distribution, the size of the labor force, and both CRS and IRS technology cost parameters. Only the lower cutoff of the middle class depends on prior economic growth. In fact, the higher the past economic growth, the lower the lower bound of the middle class $\widetilde{\gamma}(t)$ or, equivalently, the larger the size of the middle class.

More specifically, at time $t$, the size of the middle class $\widetilde{N}(t)-N^{*}$ is an increasing function of compound growth for good $\widetilde{q}$ over its learning period and, as a consequence, of past aggregate economic growth. To see this, note that implicit differentiation of (17) and use of (18) for $\widetilde{\gamma}(t)>\gamma$ yields:

$$
\frac{d\left(\gamma^{*}-\widetilde{\gamma}(t)\right)}{d g(\widetilde{q}, \check{t})}>0 \Rightarrow \frac{d \widetilde{N}(t)}{d g(\widetilde{q}, \check{t})}>0, \text { with } t^{*}(\widetilde{q}) \leq \check{t} \leq t
$$

Hence, the delimitation of the size of the middle class and its relative position in the income hierarchy are explicitly derived from past economic growth.

\subsection{The steady-state growth rate and the size and share of total income of the middle class}

We are now in a position to determine the aggregate growth rate and both the size and share of total income of the middle class in the steady-state equilibrium. First, it must be noted that in the steady state, we have (see $(8))$ :

$$
g=\frac{\dot{A}(t)}{A(t)}=\frac{\dot{y}(t)}{y(t)}=\frac{\dot{q}^{*}(t)}{q^{*}(t)}=\text { constant }
$$

Once it is recognized that the middle class is not only an input, but also an outcome of economic growth, we can establish the following proposition.

Proposition 2 The size and share of total income of the middle class in the steady-state equilibrium depend on aggregate economic growth $g$, such that $\widetilde{\gamma}$ is time-independent and satisfies the following equality:

$$
\begin{aligned}
& \frac{g}{\lambda}=\int_{\widetilde{\gamma}}^{\gamma^{*}} \frac{[1-F(\gamma)] L}{\gamma} d \gamma=N^{*} \ln \left(\gamma^{*}\right)-\widetilde{N} \ln (\widetilde{\gamma})+\int_{\widetilde{\gamma}}^{\gamma^{*}} \ln (\gamma) f(\gamma) L d \gamma, \\
& \text { with } \widetilde{N}=[1-F(\widetilde{\gamma})] L \text { and } \widetilde{T}=\int_{\widetilde{\gamma}}^{\gamma^{*}} \gamma f(\gamma) L d \gamma
\end{aligned}
$$


Proof. Note that $\gamma^{*}=\widetilde{\gamma}\left(t^{*}(\widetilde{q})\right)=\widetilde{q}(t) / y\left(t^{*}(\widetilde{q})\right) L$, with $y(v)=y\left(t^{*}(\widetilde{q})\right) \exp (-g(v-$ $\left.t^{*}(\widetilde{q})\right)$ for $t^{*}(\widetilde{q}) \leq v \leq t$. This implies that $\widetilde{\gamma}(v)=\gamma^{*} \exp \left(-g\left(v-t^{*}(\widetilde{q})\right)\right.$. Total differentiation of the latter leads to

$$
d \widetilde{\gamma}(v)=-\gamma^{*} \exp \left(-g\left(v-t^{*}(\widetilde{q})\right) g d v=-\widetilde{\gamma}(v) g d v \Leftrightarrow d v=-\frac{d \widetilde{\gamma}(v)}{\widetilde{\gamma}(v) g} .\right.
$$

By replacing in (16), we obtain

$$
\int_{\widetilde{\gamma}}^{\gamma^{*}} \frac{[1-F(\gamma)] L}{\gamma} d \gamma=\frac{g}{\lambda} .
$$

Integrating by parts $\int_{\widetilde{\gamma}}^{\gamma^{*}}([1-F(\gamma)] L / \gamma) d \gamma$ then yields $(20)$.

The model therefore provides an example of an economic relationship between middle-class-led consumption and aggregate economic growth, where the former plays a key role in the latter, while past economic growth determines both the size and the income share of the middle class. In the steady-state, we obtain the following solutions $(g, \widetilde{\gamma})$ to equations (14) and (20):

$$
\left\{\begin{array}{c}
g / \lambda=\widetilde{E} L \frac{M}{\alpha}\left[\gamma^{*} N^{*}+T-[\widetilde{\gamma} \widetilde{N}+\widetilde{T}]\right] \\
g / \lambda=N^{*} \ln \left(\gamma^{*}\right)-\widetilde{N} \ln (\widetilde{\gamma})+\int_{\widetilde{\gamma}}^{\gamma^{*}} \ln (\gamma) f(\gamma) L d \gamma
\end{array}\right.
$$

with $\widetilde{N}=[1-F(\widetilde{\gamma})] L$ and $\widetilde{T}=\int_{\widetilde{\gamma}}^{\gamma^{*}} \gamma f(\gamma) L d \gamma$.

In the next section, we study these conditions in terms of inequality and the values of the various parameters for which there will be positive longterm economic growth, as well as the trade-off underlying the inverted-U relationship between inequality and growth.

\section{Bounded learning by doing, inequality, and sustained growth in the long run}

From that point on, conditions regarding the parameters of both the CRS and IRS production functions, the size of the labor force, and the income distribution are crucial to ensuring that there is sustained growth in the long run. This requires that certain conditions be met. 


\subsection{Necessary and sufficient conditions for sustained growth}

The system of equations (21) can be written as follows:

$$
g=\Lambda(g)=\lambda \widetilde{E} L \frac{M}{\alpha}\left[\gamma^{*} N^{*}+T-[\widetilde{\gamma}(g) \widetilde{N}(g)+\widetilde{T}(g)]\right] \text { for } \widetilde{\gamma}>\underline{\gamma}
$$

where $\widetilde{\gamma}(g), \widetilde{N}(g)$, and $\widetilde{T}(g)$ are implicitly defined by equation (20).

First, differentiation of equation (22) implies that

$$
\frac{d \Lambda(g)}{d g}=-\frac{\lambda \widetilde{E} L}{\alpha} M\left[\widetilde{N}(g)+\widetilde{\gamma}(g) \frac{d \widetilde{N}(g)}{d \widetilde{\gamma}(g)}+\frac{d \widetilde{T}(g)}{d \widetilde{\gamma}(g)}\right] \frac{d \widetilde{\gamma}(g)}{d g} .
$$

Using equation $(20)$ and both $\widetilde{N}=[1-F(\widetilde{\gamma})] L$ and $\widetilde{T}=\int_{\underline{\gamma}}^{\widetilde{\gamma}} \gamma f(\gamma) L d \gamma$, we obtain $d \widetilde{\gamma}(g) / d g, d \widetilde{N}(g) / d \widetilde{\gamma}(g)$, and $d \widetilde{T}(g) / d \widetilde{\gamma}(g)$, respectively, which are replaced in (23) to obtain

$$
\frac{d \Lambda(g)}{d g}>0 \text { and } \frac{d^{2} \Lambda(g)}{d g^{2}}<0 .
$$

Second, note from (20) that

$$
\widetilde{\gamma}=\gamma^{*} \Leftrightarrow g=0 \Rightarrow \Lambda(0)=0, \quad \text { and } \lim _{g \rightarrow \infty} \widetilde{\gamma}(g)=0 \Rightarrow \lim _{g \rightarrow \infty} d \Lambda(g) / d g=0 .
$$

Hence, there exists one fixed point that exhibits positive growth if

$$
\left.\frac{d \Lambda(g)}{d g}\right|_{g=0}>1 \text { and }\left.\frac{d \Lambda(g)}{d g}\right|_{g \neq 0, g=\Lambda(g)}<1 \Leftrightarrow \widetilde{E}>E^{c}(\alpha, C, L, F),
$$

where

$$
E^{c}(\alpha, C, L, F) \equiv \frac{\alpha}{\gamma^{*} L}\left[1-\frac{\alpha-1}{\alpha} T\right]=\frac{1}{\gamma^{*} L} \frac{\alpha}{M}
$$

\subsubsection{Economies of scale and learning possibilities for sustained growth}

Recall that learning may only occur in those sectors of activity using the IRS technology, and that it is bounded from above. The analysis then leads to the following proposition. 
Proposition 3 For there to be a fixed point with positive growth, $\widetilde{E}$ must be greater than a critical level $E^{c}($.$) , which decreases with the output multiplier$ $M$, and where $E^{c}($.$) is a decreasing function of \alpha$ and $L$ and an increasing function of $C$.

Proof. See the Appendix.

The above proposition shows that relaxing the minimal-scale restriction (see the break-even condition (7)) will yield positive growth for a lower upper bound for learning $\widetilde{E}$. The higher the fixed cost and the lower the markup and the size of the labor force, the smaller the ability of many sectors to exploit economies of scale, which in turn yields both a low output multiplier process and aggregate demand spillovers that are limited in scope. In such a situation, a higher upper bound for learning is necessary to offset the impact of either a fall in $\alpha$ and $L$ or a rise in $C$.

\subsubsection{Conditions of inequality and learning for sustained growth}

As shown in (25), the critical level $E^{c}(\alpha, C, L, F)$ also depends on the distribution of income. More specifically, it depends on both the lower and upper bounds of the middle class, that is $\widetilde{\gamma}$ and $\gamma^{*}$, respectively.

Very unequal versus perfectly egalitarian distribution of income and growth Let us consider the limiting cases of either a very unequal or almost perfectly egalitarian economy.

Proposition 4 On the one hand, there can be no growth in a very unequal economy. On the other hand, an economy that tends toward perfect equality exhibits a positive growth rate only if $\widetilde{E}>E^{c}()=.1+C / L$.

Proof. See the Appendix.

On the one hand, in a highly unequal economy where a small number of households owns nearly all of the wealth, the IRS technology is confined to a small range of sectors of activity with limited opportunities for learning. Meanwhile, the upper class consumes a wide range of goods, most of them being produced with the CRS technology. Thus, aggregate demand spillovers only have a limited scope and the ability to exploit economies of scale remains moderate. This results in a low multiplier effect. Furthermore, middleclass-led consumption determines the growth rate of the economy, which also depends on the share of income that is spent in sectors of activity where learning takes place in each period. In a very uneven economy, there are no middle-market consumers, which explains the no-growth scenario. On the 
other hand, an economy with an almost perfectly egalitarian distribution of income needs to have a large enough population and/or a low minimum scale restriction to be able to prompt the learning process and exhibit positive growth in the long run. What happens in between these two extremes is ambiguous.

Inequality, income transformation and growth How does income transformation influence the size and income position of the middle class? We have the following proposition.

Proposition 5 Given two economies where Economy I Lorenz dominates Economy II, if an income transformation from II to I increases the purchasing power of the middle and lower classes in Economy II at the expense of its upper class, Economy II will see its steady-state growth rate rise. Furthermore, an income transformation from II to I that increases the purchasing power of the lower class in Economy II at the expense of its middle class leads to a drop in the steady-state rate of growth.

Proof. The proof is based on results set out in Hemming and Keen (1983). See the Appendix for details.

Therefore, the model has implications for growth-enhancing strategies by means of specific income transformations. There is an improvement in economic growth as long as an income transformation expands the total income held by either the middle class or the lower class at the expense of the upper class. In both instances, the amount of output produced with the IRS technology increases with a decline in inequality, which means a lower share of income held by the upper class, $1-T$. At the same time, the share of income held by the rest, $L-N^{*}$, increases, expanding markets in the range $\left(0, q^{*}\right)$ and achieving corresponding economies of scale. Put differently, the share of total income spent in IRS sectors $\gamma^{*} N^{*}+T$ increases. This leads to a higher transformed output multiplier, which in turn yields greater economic efficiency thanks to larger scale economies. Eventually, this has a positive effect on economic growth.

When the income transformation increases the purchasing power of the middle class at the expense of the upper class, in addition to the rise in $T$, there is a positive middle-class size effect. It turns out that the purchasing power of the "transformed" middle class that contributes to the rate of growth increases. Not only does the multiplier rise but we also observe an improvement in the proportion of income spent in sectors of activity where there is learning potential. In the end, what matters for growth is also the relative change in $\gamma^{*} N^{*}+T$ compared with that in $\widetilde{\gamma} \widetilde{N}+\widetilde{T}$. Thus, an economy 
in which a large share of income is concentrated in the hands of the upper class such that there is no growth may experience sustainable growth through redistribution to lower classes. This growth will be driven by the positive effect of redistribution on the multiplier that in turn leads to a decline in $E^{c}($.$) .$

Let us now consider that the income transformation is at the expense of the initial middle class and that it is for the benefit of the lower class. Even though such a transformation tends to make the income distribution more equal, it has no impact on the output multiplier. Recall that lower-class households spend all of their income in sectors where learning is exhausted. It is interesting to note that the total share of post-transfer income held by the "transformed" middle class declines, which results in a smaller steady-state rate of growth. It is thus entirely possible for an economy with a Lorenzdominating distribution to be characterized by both a lower growth rate and a weaker middle class.

\subsection{Inverted-U relationship between inequality and growth}

At this stage, it is necessary to specify the distribution of income $F(\gamma)$. We adopt the Pareto distribution, which exhibits useful properties as a functional form for income distribution: $F(\gamma)=1-(\gamma / \gamma)^{\beta}$ with $\beta>1$ as the shape parameter, and $\gamma \geq \gamma>0$ as the scale parameter. The larger the value of parameter $\beta$, the more equal the distribution of income. Put differently, dispersion increases monotonically as $\beta$ decreases. Note that $\beta=\gamma(q, t) f(\gamma(q, t)) /[1-F(\gamma(q, t))]$ implies that

$$
\frac{\dot{x}(q, t)}{x(q, t)}=\beta \frac{\dot{y}(t)}{y(t)} .
$$

The income elasticity of demand addressed to each sector $q \in\left(\underline{q}(t), q^{*}(t)\right)$ is equal to the Pareto shape parameter. ${ }^{13}$ Moreover, it is constant across all sectors of activity $q>\underline{q}(t)$. In the Pareto case, the system of two equations (21) becomes

$$
\left\{\begin{array}{c}
g=\beta^{-1} \lambda \widetilde{E} L[M / \alpha][T-\widetilde{T}] \\
g=\beta^{-1} \lambda\left[\widetilde{N}-N^{*}\right]
\end{array},\right.
$$

\footnotetext{
${ }^{13}$ Another interesting property of the Pareto shape distribution in this framework is that:

$$
\beta=\frac{1-T}{1-\left(\gamma^{*} N^{*}+T\right)} .
$$
}


which leads to a solution for $\widetilde{\gamma}$ and $g$ and, consequently, for both the size of the middle class $\widetilde{N}-N^{*}$ and its share of total income $T-\widetilde{T}$. We now show that there is an inverted-U-shaped relationship between $T-\widetilde{T}$ and $\beta$. Let us take advantage of both changes in variables, $n=N / L$ and $b=(\beta-1) / \beta$. When we use the Pareto distribution, we have:

$$
T(b)-\widetilde{T}(b)=(\widetilde{n})^{b}-\left(n^{*}\right)^{b} \Rightarrow \partial\left((\widetilde{n})^{b}-\left(n^{*}\right)^{b}\right) / \partial b=(\widetilde{n})^{b} \ln \widetilde{n}-\left(n^{*}\right)^{b} \ln n^{*} .
$$

Denote $\bar{b}$ as the unique solution to

$$
\partial\left((\widetilde{n})^{b}-\left(n^{*}\right)^{b}\right) / \partial b=0 \Leftrightarrow\left(\left(\frac{\widetilde{n}}{n^{*}}\right)^{\bar{b}} \ln \widetilde{n}-\ln n^{*}\right)\left(n^{*}\right)^{\bar{b}}=0 .
$$

Furthermore, we have:

$$
\partial^{2}\left((\widetilde{n})^{b}-\left(n^{*}\right)^{b}\right) /\left.\partial b^{2}\right|_{b=\bar{b}}=\left(\frac{\widetilde{n}}{n^{*}}\right)^{\bar{b}} \ln \widetilde{n} \ln \frac{\widetilde{n}}{n^{*}} \leq 0 .
$$

Therefore, $T(b)-\widetilde{T}(b)$ has a unique maximum.

Recall now that the Gini coefficient of a Pareto distribution is equal to $1 /(2 \beta-1)$. Thus, the inequality $(\beta-1) / \beta>1 / \alpha$ yields Gini $<(\alpha-1) /(\alpha+1)$. Consider a markup of $(\alpha-1) / \alpha$, which is equal to 0.2 , meaning $\alpha=1.25$. In this particular case for $\alpha$, the above inequality is such that Gini $<0.11$. Gini coefficients across countries reveal that the assumption that $(\beta-1) / \beta<1 / \alpha$ is more realistic.

To illustrate the inverted- $\mathrm{U}$ relationship between inequality and growth in the steady state, we provide a small numerical example (presented in Figure 2 and Figure 3) where the values of the parameters are set as follows: the learning rate $\lambda$ is set to 0.1 , the labor force $L$ equals 1 , and the fixed cost $C$ and $\alpha$ are set to 0.025 and 1.25 , respectively. Thus, we have $L>C /(\alpha-1)$ and the calculations are performed for values of the parameter $(\beta-1) / \beta<$ $1 / \alpha \Leftrightarrow(\alpha-1) / \alpha \beta<1$ (see (28) in the Appendix).

This numerical example shows the inverted-U relationship between inequality as measured by $(\beta-1) / \beta$ and both $T-\widetilde{T}$ (see Figure 2$)$ and the steady-state growth rate $g$ (see Figure 3$).{ }^{14}$ It also shows that given the same level of equality, the growth rate increases with $\widetilde{E}$.

\footnotetext{
${ }^{14}$ An inverted-U relationship between inequality and growth also appears when the distribution of incomes is specified with a log-normal distribution. Graphic representations are available upon request.
} 


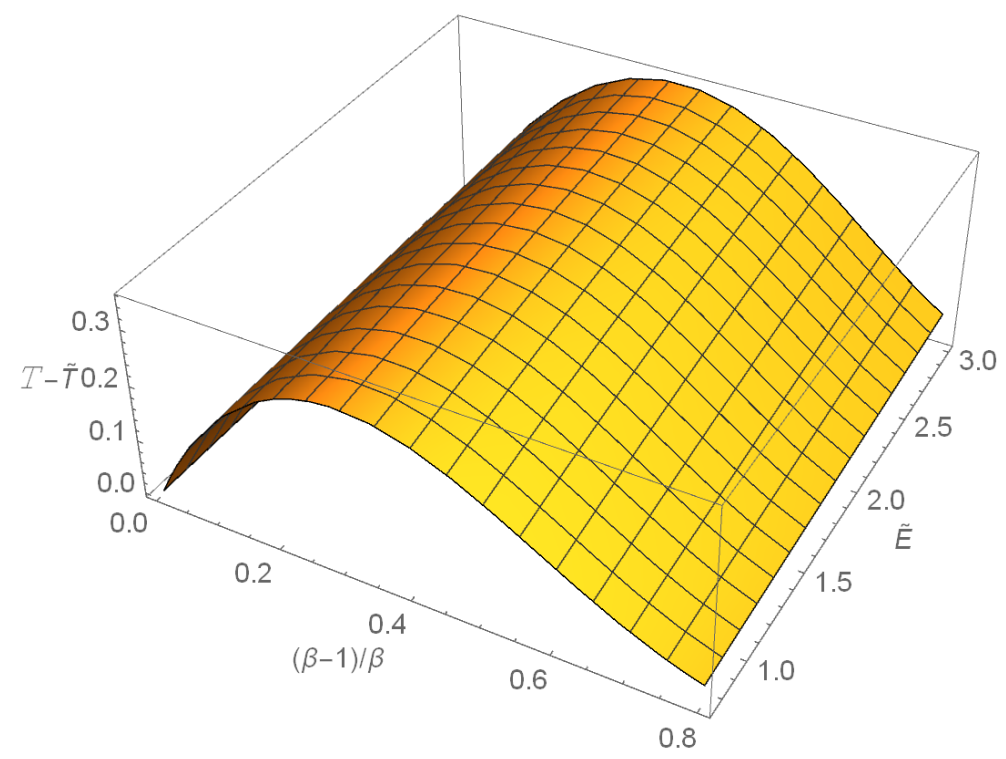

Figure 2: Inequality $(\beta-1) / \beta$, upper bound value of learning $\widetilde{E}$, and the income share of the middle class $T-\widetilde{T}$.

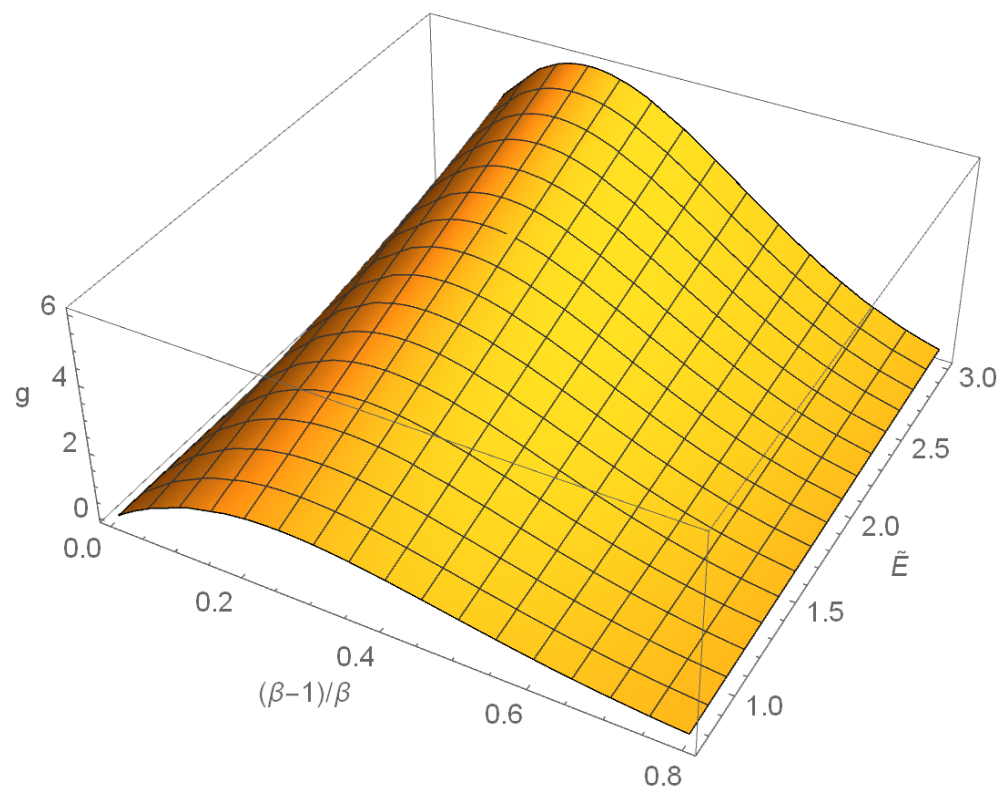

Figure 3: Inequality $(\beta-1) / \beta$, upper bound value of learning $\widetilde{E}$, and the steady-state growth rate $g$. 


\subsection{Learning by doing: the "range-speed" trade-off}

The inverted-U-shaped relationship represented in Figure 3 corroborates the idea that beyond a certain level of (in)equality, growth starts to decrease. Too much equality slows down economic growth. This is also the case for a polarized income distribution. Here, it is useful to think in terms of the way the distribution of income affects the allocation of labor across sectors where some potential for learning exists. As discussed above, a sector can learn and reach the upper bound $\widetilde{E}$ more or less rapidly depending on the rate of growth of demand for its good, which in turn depends on the income distribution. Therefore, there is a trade-off between the learning speed within a sector, which depends on the income elasticity and the range of sectors in which learning takes place $\left(\widetilde{q}(t), q^{*}(t)\right)$. An economy cannot learn both quickly and simultaneously in a wide range of sectors. It is constrained in this respect by its income/skills distribution and the size of its labor force.

Imagine that a peak arises in the distribution of income. That is, a high proportion of households in the economy now share the same $\gamma$. Furthermore, imagine that this leads to a high demand for some goods whose learning potential has not yet been exhausted. The high demand for these goods requires the allocation of a significant amount of labor to their sectors. This may be so great that not only will learning rapidly cease, but a residual part of the workforce or, equivalently, skills allocated to these sectors may generate no extra productivity; learning is indeed bounded from above. It would then be more efficient in terms of cumulative learning experience to reallocate these skills to other sectors that have not exhausted their learning potential. However, given how goods are arranged in order of decreasing hierarchy of needs, the demand for such goods may be insufficient to carry out this reallocation of labor to a downstream sector, whilst learning may be exhausted in upstream sectors. Thus, for particular values of the technical parameters, a distribution of income that either deteriorates into a very unequal distribution or approaches an almost perfectly egalitarian distribution may produce a decline in the economy's steady-state growth rate. Eventually, the trade-off consists in learning quickly in a small number of sectors versus learning more slowly in a broad range of sectors. Such a trade-off is for the most part influenced by the entire distribution of income, which governs the product cycle.

On the one hand, the lack of economies of scale hurts non-egalitarian societies with a small elite, which in turn prevents technology maturation through learning by doing. On the other hand, in a society characterized by an egalitarian distribution of income, the learning process occurs rapidly; however, it is confined to a small number of sectors that attract most (too 
much) of the labor force, eventually preventing the economy from moving ahead. This refers primarily to what we call a "range-speed" of learning trade-off.

\section{Conclusion}

The purpose of this paper is to offer a compelling theory of middle-class-led economic growth. Our framework provides, in a stylized way, an economic relationship between middle-class-led consumption and multi-sector growth, where the latter depends on both the size of the middle class and its share of total income, the delimitation of the size of the middle class and its relative position in the income hierarchy being explicitly derived from past economic growth. If the middle class is "too small," an economy may stagnate, hence the hump-shaped relationship between inequality and growth.

The model relies on the capacity of income (re)distribution to drive a dynamic big push switching of technologies from small- to large-scale production thanks to middle-class-led learning by doing in the modern sectors. Our assumption about the product life cycle differs from existing related models like innovation-based or trickle-down models. We argue that it is probably more appropriate to account for the economic development of countries in which either innovation is still limited like in developing countries, or in which a trickle-down process is unlikely to take place (e.g. because of a large income gap between the upper and the middle class). In light of the available empirical evidence, we would like, however, to emphasize that these demand-side family models of growth are not necessarily in competition, but one should rather see them as complementary in order to better understand the complexity of the inequality-growth nexus. After all, this also applies to supply-side family models that examine this nexus depending on whether they rely on the investment capacity of households at the top of the income distribution, or on credit constraints encountered by households at the bottom end of the distribution. $^{15}$

We also show that there is a labor/skills allocation trade-off in terms of the range of sectors in which learning may occur simultaneously versus the speed at which learning takes place in each sector of activity. This "range-speed" trade-off depends on the entire distribution of income and, more specifically, on the survival function, which determines the pace of learning in a sector of activity. Thus, there is a level of inequality, measured here by the shape para-

\footnotetext{
${ }^{15}$ The collection of articles compiled in Inequality and economic development: The modern perspective, 2009, and its introduction by Galor, provides an overview of these supplyside models.
} 
meter of the survival function, namely the income elasticity of demand, which maximizes economic growth. This trade-off yields an inverted-U-shaped relationship between inequality and growth where beyond a certain level of (in)equality, growth starts to decrease. As long as redistribution expands the middle and lower classes (i.e. "the rest") at the expense of the upper class, growth increases. Hence, our model also has empirically relevant implications for growth-enhancing policies by means of specific transformations of the income distribution. Needless to say at this stage, empirical research to further investigate the nexus between middle-class-led consumption/learning and multi-sector growth, particularly in unequal developing countries where $\mathrm{R} \& \mathrm{D}$ expenditure remains scarce and where the income gap between the rich and the rest of the population is still high, is deeply needed.

\section{References}

1. Acemoglu, D., and J.A. Robinson (2000). Why did the West extend the franchise? Democracy, inequality, and growth in historical perspective. The Quarterly Journal of Economics, 115(4): 1167-1199.

2. Adelman, I., and C.T. Morris (1967). Society, politics, and economic development: A quantitative approach. Baltimore: John Hopkins Press.

3. Argote, L., and D. Epple (1990). Learning curves in manufacturing. Science, 247: 920-924.

4. Atkinson, A.B., and A. Brandolini (2013). On the identification of the middle class. In Gornick, J.C., and Jantti, M. (eds.), Income inequality: economic disparities and the middle class in affluent countries. Stanford University Press.

5. Bahk, B-H., and M. Gort (1993). Decomposing learning by doing in new plants. Journal of Political Economy, 101(4): 561-583.

6. Banerjee, A.V., and E. Duflo (2003). Inequality and growth: What can the data say? Journal of Economic Growth, 8(3): 267-299.

7. Banerjee, A.V., and E. Duflo (2008). What is middle class about the middle classes around the world? Journal of Economic Perspectives, 22(2): 3-28.

8. Bertola, G., R. Foellmi, and J. Zweimüller (2006). Income distribution in macroeconomic models. Princeton University Press. 
9. Bessen, J. (2015). Learning by doing: The real connection between innovation, wages, and wealth. Yale University Press.

10. Birdsall, N. (2010). The (indispensable) middle class in developing countries; or, the rich and the rest, not the poor and the rest. In Kanbur, R., and Spence, M. (eds.), Equity and growth in a globalizing world. Washington DC: The World Bank.

11. Boppart, T. (2014). Structural change and the Kaldor facts in a growth model with relative price effects and non-Gorman preferences. Econometrica, 82(6): 2167-2196.

12. Bourguignon, F., and T. Verdier (2000) Oligarchy, democracy, inequality and growth. Journal of Development Economics, 62(2): 285-313.

13. Comin, D., D. Lashkari, and M. Mestieri (2017). Structural change with long-run income and price effects. CEPR Discussion Papers 12458.

14. Crafts, N.F.R. (1996). The First Industrial Revolution: A guided tour for growth economists. AEA Papers and Proceedings, 86(2): 197-201.

15. Dallinger, U. (2013). The endangered middle class? A comparative analysis of the role played by income redistribution. Journal of European Social Policy, 23(1): 83-101.

16. Desdoigts, A., and F. Jaramillo (2009). Trade, demand spillovers, and industrialization: The emerging global middle class in perspective. Journal of International Economics, 79(2): 248-258.

17. Easterly, W. (2001). The middle class consensus and economic development. Journal of Economic Growth, 6(4): 317-335.

18. Falkinger, J., and J. Zweimüller (1996). The cross-country Engel curve for product diversification. Structural Change and Economic Dynamics, 7: 79-97.

19. Foellmi, R., and J. Zweimüller (2006). Income distribution and demandinduced innovations. Review of Economic Studies, 73(4): 941-960.

20. Foellmi, R., T. Wuergler, and J. Zweimüller (2014). The macroeconomics of Model T. Journal of Economic Theory, 153(C): 617-647.

21. Galor, O. (2009). Inequality and economic development: An overview. In Galor, O., and Goldberger, H.H. (eds.), Inequality and economic development: The modern perspective. The international library of critical writings in economics 237. Edward Elgar Publishing. 
22. Halter, D., M. Oechlin, and J. Zweimüller (2014). Inequality and growth: The neglected time dimension. Journal of Economic Growth, 19(1): 81-104.

23. Hemming, R., and M.J. Keen (1983). Single-crossing conditions in comparisons of tax progressivity. Journal of Public Economics, 20(3): 373-380.

24. Herrendorf, B., R. Rogerson, and Á. Valentinyi (2013). Two perspectives on preferences and structural transformation. American Economic Review, 103(7): 2752-2789.

25. Hirschman, A.O. (1958). The strategy of economic development. New Haven: Yale University Press.

26. Human Development Report (2013). The rise of the South: Human progress in a diverse world. UNDP.

27. Kuznets, S. (1955). Economic growth and income inequality. American Economic Review, 45(1): 1-28.

28. Kuznets S. (1966). Modern economic growth: Rate, structure, and spread. New Haven: Yale University Press.

29. Landes, D. (1998). The wealth and poverty of nations. New York NY: Norton.

30. Lucas, R.E. (1993). Making a miracle. Econometrica, 61(2): 251-272.

31. Matsuyama, K. (2002). The rise of mass consumption societies. Journal of Political Economy, 110(5): 1035-1070.

32. Melitz, M.J. (2001). When and how should infant industries be protected? Journal of International Economics, 66(1): 177-196.

33. Murphy, K.M., A. Shleifer, and R. Vishny (1989). Income distribution, market size, and industrialization. The Quarterly Journal of Economics, 104(3): 537-564.

34. Ravallion, M. (2010). The developing world's bulging (but vulnerable) middle class. World Development, 38(4): 445-454.

35. Rosenstein-Rodan, P.M. (1943). Problems of industrialisation of Eastern and South-Eastern Europe. Economic Journal, 53(210/211): 202211. 
36. Solow, R.M. (2005). Reflections on growth theory. In Aghion, P., and Durlauf, S.N. (eds.), Handbook of Economic Growth. Elsevier B.V.

37. Stokey, N.L. (1988). Learning by doing and the introduction of new goods. Journal of Political Economy, 96(4): 701-717.

38. Thompson, P. (2001). How much did the liberty shipbuilders learn? New evidence for an old case study. Journal of Political Economy, 109(1): 103-137.

39. Thompson, P. (2010). Learning by doing. In Hall, B.H., and Rosenberg, N. (eds.), Handbook of the Economics of Innovation. Elsevier, Amsterdam.

40. Voitchovsky, S. (2005). Does the profile of income inequality matter for economic growth? Distinguishing between the effects of inequality in different parts of the income distribution. Journal of Economic Growth, 10(3): 273-296.

41. Young, A. (1991). Learning by doing and the effects of international trade. The Quarterly Journal of Economics, 106(2): 369-405.

42. Young, A. (1993). Invention and bounded learning by doing. Journal of Political Economy, 101(3): 443-472.

43. Zeira, J., and H. Zoabi (2015). Economic growth and sector dynamics. European Economic Review, 79: 1-15.

44. Zweimüller J. (2000). Schumpeterian entrepreneurs meet Engel's law: The impact of inequality on innovation-driven growth. Journal of Economic Growth, 5(2): 185-206.

\section{Appendices}

\subsection{Price equilibrium}

Proof. On the one hand, at time $t$, a monopolist entering the market for a particular good $q$ cannot set a price higher than the competitive price without giving way to a competitive fringe of firms. On the other hand, could he seriously consider increasing profits by lowering the price unilaterally below $p(t)=\alpha w(t) / A(t)$ (i.e. while all other firms keep their price unchanged)? 
The answer is no, as long as the marginal profit satisfies the following condition:

$$
\begin{aligned}
\frac{\partial \pi(q, t)}{\partial \widehat{p}(q, t)} & =\frac{\partial \widehat{x}(q, t)}{\partial \widehat{p}(q, t)}\left[\widehat{p}(q, t)-\frac{w(t)}{A(t)}\right]+\widehat{x}(q, t)>0 \\
& \Leftrightarrow-\frac{\partial \widehat{x}(q, t)}{\partial \widehat{p}(q, t)} \frac{\widehat{p}(q, t)}{\widehat{x}(q, t)}\left[\frac{\widehat{p}(q, t)-w(t) / A(t)}{\widehat{p}(q, t)}\right]<1,
\end{aligned}
$$

with $\widehat{p}(q, t) \leq p(t)$, and where $\widehat{x}(q, t)=[1-F(\gamma(\widehat{q}, t))] L$ is the effective demand for good $q$ produced at $\widehat{p}(q, t)$. In other words, the price elasticity of demand multiplied by the price-cost margin should not exceed unity.

Let us define $\widehat{q} \leq q$ such that

$$
\frac{1}{q} \frac{1}{\widehat{p}(q, t)}=\frac{1}{\widehat{q}} \frac{1}{p(t)} \Rightarrow \widehat{q}=\frac{\widehat{p}(q, t)}{p(t)} q .
$$

Customers for the variety of good $q$ include all those that are rich enough to buy $\widehat{q}$ (i.e. households of type $\gamma \geq \gamma(\widehat{q}, t)$ where $\gamma(\widehat{q}, t)=\widehat{q}(t) / y(t) L=$ $[\widehat{p}(q, t) q] /[p(t) y(t) L])$. Let $f(\gamma)$ be the density of $\gamma$ type households. We also define $\beta(\gamma) \equiv \gamma f(\gamma) /[1-F(\gamma)]$. The price elasticity of demand for good $q$ can be written as follows

$$
\begin{aligned}
& -\frac{\partial \widehat{x}(q, t)}{\partial \widehat{p}(q, t)} \frac{\widehat{p}(q, t)}{\widehat{x}(q, t)}=\frac{f(\gamma(\widehat{q}, t)) q}{p(t) y(t)} \frac{\widehat{p}(q, t)}{[1-F(\gamma(\widehat{q}, t))] L} \\
& =\frac{f(\gamma(\widehat{q}, t)) \gamma(\widehat{q}, t)}{[1-F(\gamma(\widehat{q}, t))]) L} \frac{p(t) y(t) L}{p(t) y(t)}=\frac{\gamma(\widehat{q}, t) f(\gamma(\widehat{q}, t))}{1-F(\gamma(\widehat{q}, t))}=\beta(\gamma(\widehat{q}, t)) .
\end{aligned}
$$

We can show that using (26) and (27), we have:

$$
\begin{aligned}
-\frac{\partial \widehat{x}(q, t)}{\partial \widehat{p}(q, t)} \frac{\widehat{p}(q, t)}{\widehat{x}(q, t)}\left[\frac{\widehat{p}(q, t)-w(t) / A(t)}{\widehat{p}(q, t)}\right] & =\beta(\gamma(\widehat{q}, t))\left[\frac{\widehat{p}(q, t)-w(t) / A(t)}{\widehat{p}(q, t)}\right] \\
& <\beta(\gamma(\widehat{q}, t))\left[\frac{p(q, t)-w(t) / A(t)}{p(q, t)}\right]=\frac{\alpha-1}{\alpha} \beta(\gamma(\widehat{q}, t)) .
\end{aligned}
$$

Therefore, the following inequality provides a sufficient condition for ruling out price-cutting equilibria:

$$
\frac{\alpha-1}{\alpha} \beta(\gamma(\widehat{q}, t))<1 \Rightarrow-\frac{\partial \widehat{x}(q, t)}{\partial \widehat{p}(q, t)} \frac{\widehat{p}(q, t)}{\widehat{x}(q, t)}\left[\frac{\widehat{p}(q, t)-w(t) / A(t)}{\widehat{p}(q, t)}\right]<1 .
$$

Indeed, as long as (26) is satisfied, when a firm with access to IRS technology in industry $q$ aims to cut the price below $\alpha w(t) / A(t)$, it is unable to expand its customer base to such an extent as to compensate for the loss in profit per customer, thus discouraging price-cutting. In our framework, such a condition results in (28). The income distribution should not degenerate around any $\gamma$ type. 


\subsection{Proof of Proposition 3: scale economies, learning potential, and growth}

Proof. Using the break-even condition (7), it is easy to verify that

$$
\frac{d \gamma^{*}}{d \alpha}=\frac{1-F\left(\gamma^{*}\right)}{(\alpha-1) f\left(\gamma^{*}\right)}>0, \quad \frac{d \gamma^{*}}{d L}=\frac{1-F\left(\gamma^{*}\right)}{f\left(\gamma^{*}\right) L}>0, \quad \frac{d \gamma^{*}}{d C}=-\frac{1}{(\alpha-1) f\left(\gamma^{*}\right) L}<0,
$$

which implies that

$$
\begin{gathered}
\frac{d E^{c}(.)}{d \alpha}=\frac{1}{\gamma^{*} L}\left[1-\frac{\alpha}{\alpha-1} \frac{1-F\left(\gamma^{*}\right)}{f\left(\gamma^{*}\right) \gamma^{*}}+\left[\frac{1-F\left(\gamma^{*}\right)}{f\left(\gamma^{*}\right) \gamma^{*}}-1\right] T-\left[1-F\left(\gamma^{*}\right)\right] \gamma^{*}\right]<0 \\
\Leftrightarrow \frac{\alpha-1}{\alpha} \frac{f\left(\gamma^{*}\right) \gamma^{*}}{1-F\left(\gamma^{*}\right)}<1 \text { (see the price equilibrium section above); } \\
\frac{d E^{c}(.)}{d L}=-\left[\frac{E^{c}(.)}{\gamma^{*}}+(\alpha-1) f\left(\gamma^{*}\right)\right] \frac{\left(1-F\left(\gamma^{*}\right)\right)}{f\left(\gamma^{*}\right) L}-\frac{\alpha}{\gamma^{*}(L)^{2}}<0 ; \\
\frac{d E^{c}(.)}{d C}=\left[\frac{E^{c}(.)}{\gamma^{*}}+(\alpha-1) f\left(\gamma^{*}\right)\right] \frac{1}{(\alpha-1) f\left(\gamma^{*}\right) L}>0 .
\end{gathered}
$$

\subsection{Proof of Proposition 4: very unequal versus al- most perfectly egalitarian income distribution and growth}

Proof. First, for a very unequal distribution of income, the Lorenz curve is such that its slope tends to be zero for $\gamma \leq \gamma \leq \gamma^{*}$. Thus, we have $\gamma \approx \widetilde{\gamma} \approx \gamma^{*} \approx 0$ which implies both $T \approx \widetilde{T} \approx 0$ and $M \approx 1$. Replacing in (14) immediately leads to $g=0$. Second, for an almost perfectly egalitarian distribution of income, the Lorenz curve approaches the $45^{\circ}$ line, and we have $\underline{\gamma} \approx \gamma^{*} \approx 1 / L$ which implies that $T \approx 1-N^{*} / L, \widetilde{T} \approx 0$, and $M \approx$ $\alpha /(1 \overline{+} C / L)$. Again, replacing in (14) we obtain:

$$
g=\lambda \widetilde{E} L \frac{1}{1+C / L}[1-\widetilde{\gamma} L]
$$

Using $(20)$ and $F(\gamma) \approx 0$ for $\gamma<\gamma^{*}$, we get

$$
\frac{g}{\lambda}=L \int_{\widetilde{\gamma}}^{\gamma^{*}} \frac{1}{\gamma} d \gamma=L \ln \left(\frac{1}{\widetilde{\gamma} L}\right)
$$


which implies that $\widetilde{\gamma} L=\exp (-g / \lambda L)$. Eventually, if we substitute this result into the above expression, the steady-state growth rate becomes

$$
\begin{aligned}
g & =\Lambda(g)=\lambda \widetilde{E} L \frac{1}{1+C / L}[1-\exp (-g / \lambda L)] \\
& \left.\Rightarrow \frac{d \Lambda(g)}{d g}\right|_{g=0}=\frac{\widetilde{E}}{1+C / L}>1 \Leftrightarrow \widetilde{E}>E^{c}(.)=1+\frac{C}{L}
\end{aligned}
$$

\subsection{Proof of Proposition 5: inequality, transformation of income, and growth}

The proof proceeds in two parts. The first part consists of demonstrating that an income transformation that increases the purchasing power of either the initial middle class or the lower class to the detriment of the initial upper class will produce an upward shift of $\Lambda(g)$, which eventually leads to a new equilibrium with a higher steady-state rate of growth. In the second part, we show that an income transformation that benefits the initial lower class at the expense of the initial middle class lowers economic growth.

Proof. 1.a/ Let us assume the following income transformation (see Figure 4), where the post-transfer income distribution Lorenz dominates the initial distribution of income:

$$
\gamma_{r}=\psi(\gamma, \tau)=\left\{\begin{array}{cc}
\gamma & \forall \gamma \in[\gamma, \widetilde{\gamma}[ \\
\gamma+\varphi(\gamma, \tau) & \forall \gamma \in\left[\widetilde{\gamma}, \gamma^{*}\right] \\
\gamma-\rho(\gamma, \tau) & \forall \gamma \in] \gamma^{*}, \infty[
\end{array},\right.
$$

where $\psi($.$) is positive, monotone-increasing, and continuous with \gamma$ and $\tau>0$ reflecting the intensity of income redistribution, that is $\partial \varphi(\gamma, \tau) / \partial \tau \geq 0$ and $\partial \rho(\gamma, \tau) / \partial \tau \leq 0$. In addition, we have $\widetilde{\gamma}_{r}=\widetilde{\gamma}$ and $\gamma_{r}^{*}=\gamma^{*}$, which implies that $\varphi(\widetilde{\gamma}, \tau)=\varphi\left(\gamma^{*}, \tau\right)=\rho\left(\gamma^{*}, \tau\right)=0$ and $\int_{\widetilde{\gamma}}^{\gamma^{*}} \varphi(\gamma, \tau) f(\gamma) d \gamma=$ $\int_{\gamma^{*}}^{\infty} \rho(\gamma, \tau) f(\gamma) d \gamma$. First, such an income transformation verifies the singlecrossing condition (see Hemming and Keen 1983, p. 374) such that a higher $\tau$ shifts the Lorenz curve further toward the line of perfect equality. Second, note that it implies that $F_{r}\left(\gamma_{r}\right)=F(\gamma)$. Then, using $d \gamma_{r}=\frac{\partial \psi(\gamma, \tau)}{\partial \gamma} d \gamma$, we get

$$
d F_{r}\left(\gamma_{r}\right)=d F(\gamma) \Rightarrow f_{r}\left(\gamma_{r}\right)=f(\gamma)\left(\frac{\partial \psi(\gamma, \tau)}{\partial \gamma}\right)^{-1}
$$




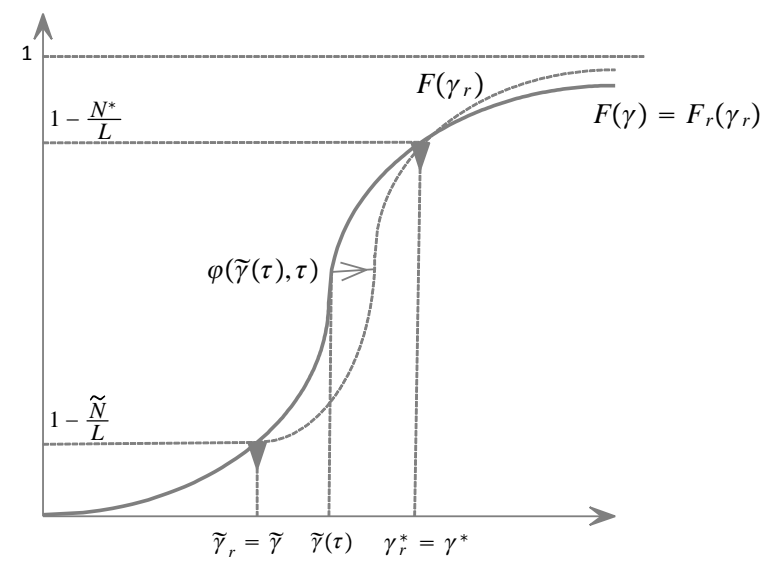

Figure 4: Income transformation from the upper to the middle class.

Finally, the middle-class share of post-transfer income becomes:

$T_{r}\left(\gamma_{r}^{*}, \tau\right)=\int_{\underline{\gamma}_{r}}^{\gamma_{r}^{*}} \gamma_{r} f_{r}\left(\gamma_{r}\right) d \gamma_{r}=\int_{\underline{\gamma}}^{\gamma^{*}} \psi(\gamma, \tau) f(\gamma) d \gamma=T\left(\gamma^{*}\right)+\int_{\widetilde{\gamma}}^{\gamma^{*}} \varphi(\gamma, \tau) f(\gamma) d \gamma$.

Let $\gamma_{r}^{*}(\tau)$ be the implicit solution to $1-F_{r}\left(\gamma_{r}^{*}(\tau)\right)=C /((\alpha-1) L)$, where $\gamma_{r}^{*}(\tau)$ is the post-transfer income of household of type- $\gamma^{*}(\tau)$, which is equal to $\psi^{-1}\left(\gamma_{r}^{*}(\tau)\right)$ and defined as the upper cutoff for the middle class after transformation. Given that $1-F\left(\gamma^{*}\right)=C /((\alpha-1) L)$ and $\gamma_{r}^{*}(\tau)=$ $\psi\left(\gamma^{*}(\tau)\right)=\gamma^{*}(\tau)$, we get $\gamma_{r}^{*}(\tau)=\gamma^{*}(\tau)=\gamma^{*}$.

We now analyze the effect of an income transformation on $\Lambda(g)$ (see (22)). The system of equations (21) can be rewritten in terms of both the transformed multiplier $M_{r}(\tau)$ and the post-transfer middle-class share of total income denoted by $\mathbb{N}(\widetilde{\gamma}(\tau), \tau)$ :

$$
\begin{aligned}
g= & \Lambda(\widetilde{\gamma}(\tau), \tau)=\lambda \widetilde{E} L \frac{M_{r}(\tau)}{\alpha} \mathbb{N}(\widetilde{\gamma}(\tau), \tau) \\
g / \lambda= & \Gamma(\widetilde{\gamma}(\tau), \tau) \\
= & N^{*} \ln \left(\gamma^{*}\right)-[1-F(\widetilde{\gamma}(\tau))] L \ln (\widetilde{\gamma}(\tau)+\varphi(\widetilde{\gamma}(\tau), \tau)) \\
& +\int_{\widetilde{\gamma}(\tau)}^{\gamma^{*}} \ln (\gamma+\varphi(\gamma, \tau)) f(\gamma) L d \gamma
\end{aligned}
$$

where $\widetilde{\gamma}(\tau)=\widetilde{\gamma}(g, \tau)$ is the implicit solution to (30) so that the household of $\widetilde{\gamma}(\tau)$ type is the new lower cutoff for the middle class after transformation, $\mathbb{N}(\widetilde{\gamma}(\tau), \tau) \equiv \int_{\widetilde{\gamma}_{r}(\tau)}^{\gamma^{*}}\left[1-F_{r}\left(\gamma_{r}\right)\right] L d \gamma_{r}$, and $\widetilde{\gamma}_{r}(\tau)=\widetilde{\gamma}(\tau)+\varphi(\widetilde{\gamma}(\tau), \tau)$ is the 
post-transfer income of household of type $\widetilde{\gamma}(\tau)$. The righ-hand side of (30) is the result of the integration by part of $\int_{\widetilde{\gamma}_{r}(\tau)}^{\gamma^{*}} \frac{1-F_{r}\left(\gamma_{r}\right)}{\gamma_{r}} d \gamma_{r}$.

Total differentiation of (29) leads to

$$
d g=\frac{\lambda \widetilde{E} L}{\alpha}\left[\begin{array}{c}
\frac{\partial M_{r}(\tau)}{\partial \tau} \mathbb{N}(\widetilde{\gamma}(\tau), \tau)+M_{r}(\tau) \frac{\partial \mathbb{N}(\widetilde{\gamma}(\tau), \tau)}{\partial \tau} d \tau \\
+M_{r}(\tau)\left[\frac{\partial \mathbb{N}(\widetilde{\gamma}(\tau), \tau)}{\partial \widetilde{\gamma}(\tau)} \frac{\partial \widetilde{\gamma}(g, \tau)}{\partial g} d g+\frac{\partial \mathbb{N}(\widetilde{\gamma}(\tau), \tau)}{\partial \widetilde{\gamma}(\tau)} \frac{\partial \widetilde{\gamma}(g, \tau)}{\partial \tau} d \tau\right]
\end{array}\right] .
$$

Therefore, we have

$$
\begin{aligned}
\frac{d g / d \tau}{g}= & {\left[1-\lambda \widetilde{E} L \frac{M_{r}(\tau)}{\alpha} \frac{\partial \mathbb{N}(\widetilde{\gamma}(\tau), \tau)}{\partial \widetilde{\gamma}(\tau)} \frac{\partial \widetilde{\gamma}(g, \tau)}{\partial g}\right]^{-1} } \\
& {\left[\frac{\frac{\partial M_{r}(\tau)}{\partial \tau}}{M_{r}(\tau)}+\frac{\frac{\partial \mathbb{N}(\widetilde{\gamma}(\tau), \tau)}{\partial \tau}+\frac{\partial \mathbb{N}(\widetilde{\gamma}(\tau), \tau)}{\partial \widetilde{\gamma}(\tau)} \frac{\partial \widetilde{\gamma}(g, \tau)}{\partial \tau}}{\mathbb{N}(\widetilde{\gamma}(\tau), \tau)}\right] }
\end{aligned}
$$

First, note that

$$
\lambda \widetilde{E} L \frac{M_{r}(\tau)}{\alpha} \frac{\partial \mathbb{N}(\widetilde{\gamma}(\tau), \tau)}{\partial \widetilde{\gamma}(\tau)} \frac{\partial \widetilde{\gamma}(g, \tau)}{\partial g}=\lambda \widetilde{E} L \frac{M_{r}(\tau)}{\alpha}(\widetilde{\gamma}(\tau)+\varphi(\widetilde{\gamma}(\tau), \tau)),
$$

where $\partial \widetilde{\gamma}(g, \tau) / \partial g$ is the implicit derivative of $\widetilde{\gamma}(g, \tau)$ using (30):

$$
\frac{\partial \widetilde{\gamma}(g, \tau)}{\partial g}=\frac{1}{\lambda}\left[\frac{\partial \Gamma(\widetilde{\gamma}(\tau), \tau)}{\partial \widetilde{\gamma}(\tau)}\right]^{-1} .
$$

Using properties of $\Lambda(g)$ as discussed in Section 5.1, we infer that for $g$ such that $\Lambda(g, \tau)=g$, we have $\partial \Lambda(g, \tau) / \partial g<1$, where

$$
\frac{\partial \Lambda(g, \tau)}{\partial g}=\lambda \widetilde{E} L \frac{M_{r}(\tau)}{\alpha}(\widetilde{\gamma}(\tau)+\varphi(\widetilde{\gamma}(\tau), \tau))
$$

which implies that

$$
\left[1-\frac{\lambda \widetilde{E} L}{\alpha} M_{r}(\tau) \frac{\partial \mathbb{N}(\widetilde{\gamma}(\tau), \tau)}{\partial \widetilde{\gamma}(\tau)} \frac{\partial \widetilde{\gamma}(g, \tau)}{\partial g}\right]^{-1}>0 .
$$

Second, the transformed multiplier is given by

$$
\begin{aligned}
M_{r}(\tau) & =\frac{1}{1-\frac{\alpha-1}{\alpha}\left[T\left(\gamma^{*}\right)+\int_{\widetilde{\gamma}(\tau)}^{\gamma^{*}} \varphi(\gamma, \tau) f(\gamma) d \gamma\right]} \\
& \Rightarrow \frac{\partial M_{r}(\tau) / \partial \tau}{M_{r}(\tau)}=M_{r} \frac{\alpha-1}{\alpha} \int_{\widetilde{\gamma}(\tau)}^{\gamma^{*}} \frac{d \varphi(\gamma, \tau)}{d \tau} f(\gamma) d \gamma>0
\end{aligned}
$$


Finally, the share of total income held by those households that are now part of the "transformed" middle class can be written as

$$
\begin{aligned}
\mathbb{N}(\widetilde{\gamma}(\tau), \tau)= & \gamma^{*} N^{*}-[\widetilde{\gamma}(\tau)+\varphi(\widetilde{\gamma}(\tau), \tau)][1-F(\widetilde{\gamma}(\tau))] L \\
& +T\left(\gamma^{*}\right)-T(\widetilde{\gamma}(\tau))+\int_{\widetilde{\gamma}(\tau)}^{\gamma^{*}} \varphi(\gamma, \tau) f(\gamma) L d \gamma .
\end{aligned}
$$

Given that

$$
\frac{\partial \widetilde{\gamma}(g, \tau)}{\partial \tau}=-\frac{\partial \Gamma(\widetilde{\gamma}(\tau), \tau) / \partial \tau}{\partial \Gamma(\widetilde{\gamma}(\tau), \tau) / \partial \widetilde{\gamma}(\tau)}
$$

we get

$$
\begin{aligned}
& \frac{\partial \mathbb{N}(\widetilde{\gamma}(\tau), \tau)}{\partial \tau}+\frac{\partial \mathbb{N}(\widetilde{\gamma}(\tau), \tau)}{\partial \widetilde{\gamma}(\tau)} \frac{\partial \widetilde{\gamma}(g, \tau)}{\partial \tau} \\
= & \int_{\widetilde{\gamma}(\tau)}^{\gamma^{*}}\left[1-\frac{\widetilde{\gamma}(\tau)+\varphi(\widetilde{\gamma}(\tau), \tau)}{\gamma+\varphi(\gamma, \tau)}\right] \frac{\partial \varphi(\gamma, \tau)}{\partial \tau} f(\gamma) L d \gamma>0 \\
\Leftrightarrow & \gamma+\varphi(\gamma, \tau)>\widetilde{\gamma}(\tau)+\varphi(\widetilde{\gamma}(\tau), \tau), \text { for } \widetilde{\gamma}(\tau)<\gamma<\gamma^{*} .
\end{aligned}
$$

1.b/ We use the same approach to prove that an income transformation, which increases the purchasing power of the initial lower class at the expense of the upper class will lead to a rise in the steady-state growth rate. Here, we assume the following income transformation:

$$
\gamma_{r}=\psi(\gamma, \tau)=\left\{\begin{array}{cc}
\gamma+\varphi(\gamma, \tau) & \forall \gamma \in[\gamma, \widetilde{\gamma}[ \\
\gamma & \forall \gamma \in\left[\widetilde{\gamma}, \gamma^{*}\right] \\
\gamma-\rho(\gamma, \tau) & \forall \gamma \in] \gamma^{*}, \infty[
\end{array},\right.
$$

where $\psi($.$) is again positive, monotone-increasing and continuous with \gamma$, both $\widetilde{\gamma}_{r}=\widetilde{\gamma}$ and $\gamma_{r}^{*}=\gamma^{*}$ imply that $\varphi(\widetilde{\gamma}, \tau)=\rho\left(\gamma^{*}, \tau\right)=0$, and $\int_{\underline{\gamma}}^{\widetilde{\gamma}} \varphi(\gamma, \tau) f(\gamma) d \gamma=$ $\int_{\gamma^{*}}^{\infty} \rho(\gamma, \tau) f(\gamma) d \gamma$. Such an income transformation also verifies the singlecrossing condition and implies that $F_{r}\left(\gamma_{r}\right)=F(\gamma)$. The middle-class share of post-transfer income is now given by

$$
T_{r}\left(\gamma^{*}, \tau\right)=\int_{\underline{\gamma}}^{\widetilde{\gamma}} \psi(\gamma, \tau) f(\gamma) d \gamma=T\left(\gamma^{*}\right)+\int_{\underline{\gamma}}^{\widetilde{\gamma}} \varphi(\gamma, \tau) f(\gamma) d \gamma .
$$

In this case, (30) is given by

$$
\begin{aligned}
\Gamma(\widetilde{\gamma}(\tau), \tau)= & N^{*} \ln \left(\gamma^{*}\right)-[1-F(\widetilde{\gamma}(\tau))] L \ln (\widetilde{\gamma}(\tau)+\varphi(\widetilde{\gamma}(\tau), \tau)) \\
& +\int_{\widetilde{\gamma}(\tau)}^{\widetilde{\gamma}} \ln (\gamma+\varphi(\gamma, \tau)) f(\gamma) L d \gamma+\int_{\widetilde{\gamma}}^{\gamma^{*}} \ln (\gamma) f(\gamma) L d \gamma .
\end{aligned}
$$


We show that:

$$
\frac{\partial M_{r}(\tau)}{\partial \tau}>0 \quad \text { and } \frac{\partial \mathbb{N}(\widetilde{\gamma}(\tau), \tau)}{\partial \tau}+\frac{\partial \mathbb{N}(\widetilde{\gamma}(\tau), \tau)}{\partial \widetilde{\gamma}(\tau)} \frac{\partial \widetilde{\gamma}(g, \tau)}{\partial \tau}>0,
$$

which given (31) implies that $d g / g>0$. On the one hand, we have

$$
\begin{aligned}
M_{r}(\tau) & =\left[1-\frac{\alpha-1}{\alpha}\left[T\left(\gamma^{*}\right)+\int_{\underline{\gamma}}^{\widetilde{\gamma}} \varphi(\gamma, \tau) f(\gamma) d \gamma\right]\right]^{-1} \\
& \Rightarrow \frac{\partial M_{r}(\tau) / \partial \tau}{M_{r}(\tau)}=M_{r}(\tau) \frac{\alpha-1}{\alpha} \int_{\underline{\gamma}}^{\widetilde{\gamma}} \frac{\partial \varphi(\gamma, \tau)}{\partial \tau} f(\gamma) L d \gamma>0 .
\end{aligned}
$$

On the other hand, the post-transfer middle-class share of total income is given by $^{16}$

$$
\begin{aligned}
\mathbb{N}(\widetilde{\gamma}(\tau), \tau)= & \gamma^{*} N^{*}-[1-F(\widetilde{\gamma}(\tau))] L(\widetilde{\gamma}(\tau)+\varphi(\widetilde{\gamma}(\tau), \tau)) \\
& +T\left(\gamma^{*}\right)-T(\widetilde{\gamma}(\tau))+\int_{\widetilde{\gamma}(\tau)}^{\gamma}(\gamma, \tau) f(\gamma) L d \gamma \\
\Rightarrow & \frac{\partial \mathbb{N}(\widetilde{\gamma}(\tau), \tau)}{\partial \tau}+\frac{\partial \mathbb{N}(\widetilde{\gamma}(\tau), \tau)}{\partial \widetilde{\gamma}(\tau)} \frac{\partial \widetilde{\gamma}(g, \tau)}{\partial \tau} \\
= & \int_{\widetilde{\gamma}(\tau)}^{\widetilde{\gamma}}\left(1-\frac{\widetilde{\gamma}(\tau)+\varphi(\widetilde{\gamma}(\tau), \tau)}{\gamma+\varphi(\gamma, \tau)}\right) \frac{\partial \varphi(\gamma(\tau), \tau)}{\partial \tau} f(\gamma) L d \gamma>0 \\
\Leftrightarrow & \gamma+\varphi(\gamma, \tau)>\widetilde{\gamma}(\tau)+\varphi(\widetilde{\gamma}(\tau), \tau), \text { for } \widetilde{\gamma}(\tau)<\gamma<\widetilde{\gamma} .
\end{aligned}
$$

2/ We now assume:

$$
\gamma_{r}=\psi(\gamma, \tau)=\left\{\begin{array}{cc}
\gamma+\varphi(\gamma, \tau) & \forall \gamma \in[\gamma, \widetilde{\gamma}[ \\
\gamma-\rho(\gamma, \tau) & \forall \gamma \in\left[\widetilde{\gamma}, \gamma^{*}\right] \\
\gamma & \forall \gamma \in] \gamma^{*}, \infty[
\end{array},\right.
$$

where $\psi($.$) still has the same properties as above, and \int_{\underline{\gamma}}^{\widetilde{\gamma}} \varphi(\gamma, \tau) f(\gamma) d \gamma=$ $\int_{\widetilde{\gamma}}^{\gamma^{*}} \rho(\gamma, \tau) f(\gamma) d \gamma$. The middle-class share of post-transfer income is given by

$$
T_{r}\left(\gamma^{*}, \tau\right)=T\left(\gamma^{*}\right)+\int_{\underline{\gamma}}^{\widetilde{\gamma}} \varphi(\gamma, \tau) f(\gamma) d \gamma-\int_{\widetilde{\gamma}}^{\gamma^{*}} \rho(\gamma, \tau) f(\gamma) d \gamma=T\left(\gamma^{*}\right) .
$$

${ }^{16}$ We make use of the inequality $\widetilde{\gamma}(\tau)<\widetilde{\gamma}$, which can be shown using

$$
\frac{d \widetilde{\gamma}(\tau)}{d \tau}=\frac{\partial \widetilde{\gamma}(g, \tau)}{\partial g} \frac{d g}{d \tau}+\frac{\partial \widetilde{\gamma}(g, \tau)}{\partial \tau}<0
$$


Note that (30) is given by

$$
\begin{aligned}
\Gamma(\widetilde{\gamma}(\tau), \tau)= & N^{*} \ln \left(\gamma^{*}\right)-[1-F(\widetilde{\gamma}(\tau))] L \ln (\widetilde{\gamma}(\tau)+\varphi(\widetilde{\gamma}(\tau), \tau)) \\
& +\int_{\widetilde{\gamma}(\tau)}^{\widetilde{\gamma}} \ln (\gamma+\varphi(\gamma, \tau)) f(\gamma) L d \gamma+\int_{\widetilde{\gamma}}^{\gamma^{*}} \ln (\gamma-\rho(\gamma, \tau)) f(\gamma) L d \gamma
\end{aligned}
$$

Here, we show that:

$$
\frac{\partial M_{r}(\tau)}{\partial \tau}=0 \quad \text { and } \frac{\partial \mathbb{N}(\widetilde{\gamma}(\tau), \tau)}{\partial \tau}+\frac{\partial \mathbb{N}(\widetilde{\gamma}(\tau), \tau)}{\partial \widetilde{\gamma}(\tau)} \frac{\partial \widetilde{\gamma}(g, \tau)}{\partial \tau}>0
$$

which implies that $d g / g>0$. We focus on the post-transfer middle-class share of total income:

$$
\begin{aligned}
& \mathbb{N}(\widetilde{\gamma}(\tau), \tau)= N^{*} \gamma^{*}-[1-F(\widetilde{\gamma}(\tau))] L(\widetilde{\gamma}(\tau)+\varphi(\widetilde{\gamma}(\tau), \tau))+T\left(\gamma^{*}\right)-T(\widetilde{\gamma}(\tau)) \\
&+\int_{\widetilde{\gamma}(\tau)}^{\widetilde{\gamma}} \varphi(\gamma, \tau) f(\gamma) L d \gamma-\int_{\widetilde{\gamma}}^{\gamma^{*}} \rho(\gamma, \tau) f(\gamma) L d \gamma \\
& \Rightarrow \frac{\partial \mathbb{N}(\widetilde{\gamma}(\tau), \tau)}{\partial \tau}+\frac{\partial \mathbb{N}(\widetilde{\gamma}(\tau), \tau)}{\partial \widetilde{\gamma}(\tau)} \frac{\partial \widetilde{\gamma}(g, \tau)}{\partial \tau} \\
&= \int_{\widetilde{\gamma}(\tau)}^{\widetilde{\gamma}}\left(1-\frac{\widetilde{\gamma}_{r}(\tau)}{\gamma+\varphi(\gamma, \tau)}\right) \frac{\partial \varphi(\gamma(\tau), \tau)}{\partial \tau} f(\gamma) L d \gamma \\
&-\int_{\widetilde{\gamma}}^{\gamma^{*}}\left(1-\frac{\widetilde{\gamma}_{r}(\tau)}{\gamma-\rho(\gamma, \tau)}\right) \frac{\partial \rho(\gamma(\tau), \tau)}{\partial \tau} f(\gamma) L d \gamma<0
\end{aligned}
$$

recalling that $\widetilde{\gamma}_{r}(\tau)=\widetilde{\gamma}(\tau)+\varphi(\widetilde{\gamma}(\tau), \tau)$.

Note first that the following two inequalities hold:

$$
\begin{gathered}
\int_{\widetilde{\gamma}(\tau)}^{\widetilde{\gamma}}\left(1-\frac{\widetilde{\gamma}_{r}(\tau)}{\gamma+\varphi(\gamma, \tau)}\right) \frac{\partial \varphi(\gamma(\tau), \tau)}{\partial \tau} f(\gamma) d \gamma<\int_{\widetilde{\gamma}(\tau)}^{\widetilde{\gamma}}\left(1-\frac{\widetilde{\gamma}_{r}(\tau)}{\widetilde{\gamma}}\right) \frac{\partial \varphi(\gamma(\tau), \tau)}{\partial \tau} f(\gamma) d \gamma, \\
\int_{\widetilde{\gamma}}^{\gamma^{*}}\left(1-\frac{\widetilde{\gamma}_{r}(\tau)}{\widetilde{\gamma}}\right) \frac{\partial \rho(\gamma(\tau), \tau)}{\partial \tau} f(\gamma) d \gamma<\int_{\widetilde{\gamma}}^{\gamma^{*}}\left(1-\frac{\widetilde{\gamma}_{r}(\tau)}{\gamma-\rho(\gamma, \tau)}\right) \frac{\partial \rho(\gamma(\tau), \tau)}{\partial \tau} f(\gamma) d \gamma .
\end{gathered}
$$

Second, the above budget constraint leads to:

$$
\int_{\widetilde{\gamma}(\tau)}^{\widetilde{\gamma}}\left(1-\frac{\widetilde{\gamma}_{r}(\tau)}{\widetilde{\gamma}}\right) \frac{\partial \varphi(\gamma(\tau), \tau)}{\partial \tau} f(\gamma) d \gamma<\int_{\widetilde{\gamma}}^{\gamma^{*}}\left(1-\frac{\widetilde{\gamma}_{r}(\tau)}{\widetilde{\gamma}}\right) \frac{\partial \rho(\gamma(\tau), \tau)}{\partial \tau} f(\gamma) d \gamma
$$

Finally, the following inequality is obtained using the principles of transitivity:

$$
\int_{\widetilde{\gamma}(\tau)}^{\widetilde{\gamma}}\left(1-\frac{\widetilde{\gamma}_{r}(\tau)}{\gamma+\varphi(\gamma, \tau)}\right) \frac{\partial \varphi(\gamma(\tau), \tau)}{\partial \tau} f(\gamma) d \gamma<\int_{\widetilde{\gamma}}^{\gamma^{*}}\left(1-\frac{\widetilde{\gamma}_{r}(\tau)}{\gamma-\rho(\gamma, \tau)}\right) \frac{\partial \rho(\gamma(\tau), \tau)}{\partial \tau} f(\gamma) d \gamma .
$$

